\title{
Perceptual Function and Category-Selective Neural Organization in Children with Resections of Visual Cortex
}

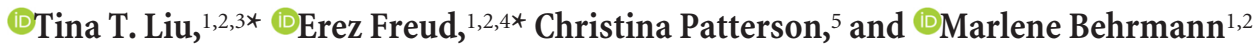 \\ ${ }^{1}$ Center for the Neural Basis of Cognition, ${ }^{2}$ Department of Psychology, Carnegie Mellon University, Pittsburgh, Pennsylvania 15213, ${ }^{3}$ Laboratory of Brain \\ and Cognition, National Institute of Mental Health, National Institutes of Health, Bethesda, Maryland 20892, ${ }^{4}$ Department of Psychology and the Centre for \\ Vision Research, York University, Toronto, Ontario M3J 1P3, Canada, and ${ }^{5}$ Department of Pediatrics, University of Pittsburgh, Pittsburgh, Pennsylvania \\ 15224
}

The consequences of cortical resection, a treatment for humans with pharmaco-resistant epilepsy, provide a unique opportunity to advance our understanding of the nature and extent of cortical (re)organization. Despite the importance of visual processing in daily life, the neural and perceptual sequellae of occipitotemporal resections remain largely unexplored. Using psychophysical and fMRI investigations, we compared the neural and visuoperceptual profiles of 10 children or adolescents following unilateral cortical resections and their age- and gender-matched controls. Dramatically, with the exception of two individuals, both of whom had relatively greater cortical alterations, all patients showed normal perceptual performance on tasks of intermediate- and high-level vision, including face and object recognition. Consistently, again with the exception of the same two individuals, both univariate and multivariate fMRI analyses revealed normal selectivity and representational structure of category-selective regions. Furthermore, the spatial organization of categoryselective regions obeyed the typical medial-to-lateral topographic organization albeit unilaterally in the structurally preserved hemisphere rather than bilaterally. These findings offer novel insights into the malleability of cortex in the pediatric population and suggest that, although experience may be necessary for the emergence of neural category-selectivity, this emergence is not necessarily contingent on the integrity of particular cortical structures.

Key words: category selectivity; cortical organization; cortical resection; epilepsy; pediatrics; visual perception

Significance Statement

One approach to reduce seizure activity in patients with pharmaco-resistant epilepsy involves the resection of the epileptogenic focus. The impact of these resections on the perceptual behaviors and organization of visual cortex remain largely unexplored. Here, we characterized the visuoperceptual and neural profiles of ventral visual cortex in a relatively large sample of post-resection pediatric patients. Two major findings emerged. First, most patients exhibited preserved visuoperceptual performance across a wide-range of visual behaviors. Second, normal topography, magnitude, and representational structure of category-selective organization were uncovered in the spared hemisphere. These comprehensive imaging and behavioral investigations uncovered novel evidence concerning the neural representations and visual functions in children who have undergone cortical resection, and have implications for cortical plasticity more generally.

\section{Introduction}

The human ventral occipitotemporal cortex (VOTC) has a well established medial-to-lateral arrangement of category-selectivity

Received Dec. 12, 2018; revised May 13, 2019; accepted May 13, 2019.

Author contributions: M.B. designed research; T.T.L. and M.B. performed research; C.P. contributed unpublished reagents/analytic tools; T.T.L. and E.F. analyzed data; E.F. and M.B. wrote the paper.

This work was supported by NIH Grant (R01 EY027018) to M.B., and by a Presidential Fellowship from Carnegie Mellon University (CMU) to T.T.L. We thank the patients, the controls, and their families for their time and cooperation; Adrian Nestor, John Pyles, and Mark Vida for their help setting up the fMRI and/or behavioral experiments; the MRI technologists Scott Kurdilla and Debbie Viszlay for their help in acquiring the imaging data; Taylor Abel for his valuable guidance; and the Vis $C$ g group at CMU for the fruitful discussions.

The authors declare no competing financial interests. bilaterally (Grill-Spector and Malach, 2004) and a clearly-defined pattern as a function of eccentricity (Hasson et al., 2002). This selectivity and topography appear to emerge early in life, revealed by both fMRI (Scherf et al., 2007; Golarai et al., 2017; Barttfeld et al., 2018; Dehaene-Lambertz et al., 2018) and functional nearinfrared spectroscopy studies (Otsuka et al., 2007; Emberson et al., 2017), and then be refined further over development (Nishimura et al., 2015; Deen et al., 2017). The correspondence

\footnotetext{
${ }^{*}$ T.T.L. and E.F. contributed equally to this work.

Correspondence should be addressed to Marlene Behrmann at behrmann@cmu.edu.

https://doi.org/10.1523/JNEUROSCI.3160-18.2019

Copyright $\odot 2019$ the authors
} 
between this cortical arrangement and perceptual behavior, and the extent to which this relationship is malleable, remains controversial. For example, a lesion to VOTC, even if circumscribed (Konen et al., 2011), results in a profound impairment in object recognition (Adolphs, 2016), whereas an extensive resection need not necessarily result in a perceptual impairment (Damásio et al., 1975; Werth, 2006). Deriving a principled account of the brainbehavior correspondence, however, is plagued by the rarity and heterogeneity of the patients.

Studies of children who have undergone surgical intervention for the treatment of pharmaco-resistant epilepsy have successfully characterized changes in intelligence (Vargha-Khadem et al., 1994), memory (Meekes et al., 2013), language (de Koning et al., 2009), and motor function (Buckley et al., 2014). Because there is greater plasticity in childhood than in adulthood, such investigations offer a unique opportunity to uncover the organization of complex brain-behavior relationships and their plasticity (Bourne, 2010). Surprisingly, despite the importance of visual functions such as face and word recognition and the large swath of cortex implicated in these processes, rather few studies explore the impact of a cortical resection on visual behavior and on the organization of the VOTC (for recent single case studies, see Weiner et al., 2016; Liu et al., 2018). Here, we examine brainbehavior relationships in vision by combining psychophysics and functional imaging methods in a relatively large series of 10 postlobectomy children or adolescents (age 6-17 years at surgery). In most cases, the cortical pathology occurred prenatally (e.g., focal dysplasia, polymicrogyria) or at birth (e.g., perinatal stroke) although the onset of seizures and consequent surgery is usually delayed by several years (Table 1).

Elucidating the nature and extent of reorganization in postresection cases addresses a range of scientific questions concerning malleability of the cortical visual system (Tracy et al., 2014), the critical period for plasticity and the factors (e.g., presurgical cognitive status) that determine postsurgical outcome. Many classical studies conducted in nonhuman primates focusing on sensory and motor cortices have demonstrated that cortical representations, even in adulthood, are modifiable by experience (Kaas, 1991; Buonomano and Merzenich, 1998). A host of explanations for these changes have been proposed including longterm potentiation and depression of excitatory postsynaptic potentials as well as selective strengthening of excitatory intracortical input (Sun et al., 2019) and Hebbian learning (Tomasello et al., 2019).

But, at least in the visual system, excessive plasticity may be disadvantageous, possibly disrupting the coordinated computational circuitry for stereoscopic depth and motion perception, or the correspondence between two representations such as those between visual and cortical space. Molecular mechanisms that stabilize the visual neural system and tamp down plasticity have also been and continue to be identified (Syken et al., 2006; Wandell and Smirnakis, 2009).

At present, it is incontrovertible that the visual system (the focus of this paper) is likely both plastic and stable. Recent studies have pointed to the necessary role of experience in shaping the topography of visual regions, including the category-selective organization of extrastriate areas (Arcaro and Livingstone, 2017; Livingstone et al., 2017; Ponce et al., 2017) and the effects of experiential deprivation on these maps (Kelly et al., 2012; Arcaro et al., 2017). Ongoing pressing questions then revolve around the time periods within which maximal plasticity occurs, whether plasticity applies to particular visual maps and whether one can promote plasticity by intervention, either behavioral or molecular (for review, see Bavelier et al., 2010).

In this paper, we focus on the plasticity of cortical visual maps in children and adolescents, presumably raised with normal experience, and examine whether a canonical neural substrate must be in situ for these extrastriate category-selective maps to emerge. To do so, we investigated the impact of a cortical resection on the visuoperceptual functions and neural organization of VOTC in patients with unilateral resections (Figs. 1, 2; Tables 1, 2). First, we compared the behavioral profiles of the patients and matched controls on psychophysical experiments probing intermediateand high-level vision, including face and object recognition. Next, univariate and multivariate analyses of the fMRI data enabled us to compare the spatial topography, functional properties, and representational basis of category-selectivity maps in the two groups.

We predicted that, similar to other cognitive functions which recover post-resection, children will largely, if not entirely, regain normal perceptual behavior, especially for behaviors that typically undergo a protracted developmental trajectory, such as face and word recognition (Liu et al., 2018). Importantly, however, this preserved or recovered behavior might be the product of the reorganization of the behaviors typically subserved by the resected regions to other ipsilesional or contralesional locations. Last, we considered whether factors such as hemisphere resected or premorbid cognitive status might affect the postsurgical outcome.

\section{Materials and Methods Participants}

We recruited 10 pediatric patients (right-handed, 5 male, average age at surgery: $12.6 \pm 3.5$ years, average age at scan: $15.0 \pm 2.5$ years) with cortical resection following medically intractable epilepsy ( 9 patients) or a single focal seizure following a neuroglial lesion in the posterior right middle frontal gyrus (1 patient: E.K.). Four patients had resections outside VOTC and had full visual fields, and served as control patients, providing a benchmark of visual function when the resection spared visual cortex (Fig. 1A): I.S. and E.K. had resections of the right frontal lobe, U.T. had a small frontal and small parietal resection in the right hemisphere (RH), and K.U. had a resection of the right parietal lobe. The other six patients had resections encompassing VOTC (Fig. 1B), three in the left hemisphere (LH; T.C., O.T., and N.N.) and three in the RH (U.D., S.F., and K.Q.). In four of the six VOTC patients, the resection impacted early visual cortex (EVC) unilaterally (LH: T.C. and N.N.; RH: U.D. and S.F.) with a resultant visual field defect ( 3 hemianopia and 1 quadrantanopia). All patients underwent surgery by the Division of Neurosurgery at Children's Hospital, Pittsburgh, PA. All were native English speakers except T.C. Table 1 lists the demographic and surgical information for each patient including their score on the Engel Epilepsy Surgery Outcome Scale (Engel, 1993). See Table 2 for additional information obtained from neuropsychological investigations for each patient. Presurgical IQ scores showed a wide range, from 40 to 122 (see S.F. IQ score of 40 and N.N. IQ score of 67); this is potentially relevant given that functional recovery can be contingent on presurgical cognitive status (Alpherts et al., 2004).

Ten age- and gender-matched typically developing controls (righthanded, 5 male, average age at scan: $14.9 \pm 3.1$ years) participated in the fMRI studies and there was no difference in age across the patients and controls $\left(F_{(1,18)}=0.010, p=0.923\right.$, one-way ANOVA). Controls were native English speakers with normal or corrected-to-normal vision and no neurological history. Four of the controls (right-handed, 2 male) also participated in the perceptual testing session and we recruited an additional three controls (right-handed, 2 male) to compare visual perception in the six VOTC patients and one patient with frontal resection (E.K.) who were amenable to this testing.

All participants provided assent and their parents provided informed consent to participate in the protocol approved by the Institutional Re- 
Table 1. Summary of patients' demographical information

\begin{tabular}{|c|c|c|c|c|c|c|c|c|c|c|c|c|c|}
\hline Group & Patient & Gender & Diagnosis/pathology & Preoperative MRI & Hemisphere & Resection & $\begin{array}{l}\text { Seizure } \\
\text { onset, y }\end{array}$ & $\begin{array}{l}\text { Age at } \\
\text { surgery, y }\end{array}$ & $\begin{array}{l}\text { Age at } \\
\text { scan, } y\end{array}$ & $\begin{array}{l}\text { Presurgical } \\
\text { IQ }\end{array}$ & $\begin{array}{l}\text { Postsurgical } \\
\text { IQ }\end{array}$ & Visual fields & $\begin{array}{l}\text { Engle epilepsy } \\
\text { surgery outcome } \\
\text { scale }^{d}\end{array}$ \\
\hline Frontal & I.S. & $\mathrm{F}$ & $\begin{array}{l}\text { Perinatal stroke with medi- } \\
\text { cally intractable focal } \\
\text { epilepsy/ulegyria }\end{array}$ & $\begin{array}{l}\text { Abnormal MRI } \\
\text { with remote } \\
\text { right MCA } \\
\text { infarct }\end{array}$ & Right & $\begin{array}{l}\text { Right frontal pole, } \\
\text { right frontal } \\
\text { operculum, and } \\
\text { right inferior } \\
\text { frontal corticec- } \\
\text { tomy }\end{array}$ & 9 & 10 & 14 & 118 & 99 & Full & IB \\
\hline Parietal & U.T. & $\mathrm{F}$ & $\begin{array}{l}\text { Medically intractable focal } \\
\text { epilepsy/FCD }\end{array}$ & Non-lesion MRI & Right & $\begin{array}{l}\text { Right premotor, } \\
\text { supplementary } \\
\text { motor, and pari- } \\
\text { etal corticectomy }\end{array}$ & 9 & 15 & 17 & 90 & 79 & Full & $\| A$ \\
\hline \multirow[t]{2}{*}{ Left VOTC } & T.C. & $\mathrm{F}$ & $\begin{array}{l}\text { Perinatal stroke with medi- } \\
\text { cally intractable focal } \\
\text { epilepsy/multifocal } \\
\text { encephalomalacia con- } \\
\text { sistent with remote } \\
\text { ischemic injury }\end{array}$ & $\begin{array}{l}\text { Abnormal MRI } \\
\text { with lesion in } \\
\text { the left occip- } \\
\text { ital lobe }\end{array}$ & Left & $\begin{array}{l}\text { Left posterior pari- } \\
\text { etal and occipital } \\
\text { lobectomy }\end{array}$ & 7 & 13 & 13 & $a$ & $a$ & $\begin{array}{l}\text { Right superior } \\
\text { quadrantanopia }\end{array}$ & IID \\
\hline & 0.T. & M & $\begin{array}{l}\text { Medically intractable focal } \\
\text { epilepsy, symptomatic } \\
\text { lesion/ganglioglioma, } \\
\text { FCD }\end{array}$ & $\begin{array}{l}\text { Abnormal MRI } \\
\text { with lesion in } \\
\text { the medial } \\
\text { left temporal } \\
\text { lobe }\end{array}$ & Left & $\begin{array}{l}\text { Medial left temporal } \\
\text { lobe gross total } \\
\text { tumor resection } \\
\text { and left temporal } \\
\text { lobectomy with } \\
\text { preservation of } \\
\text { medial structures }\end{array}$ & 12 & 13 & 14 & 122 & 127 & Full & IA \\
\hline \multirow{2}{*}{ Right VOTC } & S.F. & $\mathrm{F}$ & $\begin{array}{l}\text { Perinatal stroke with medi- } \\
\text { cally intractable focal } \\
\text { epilepsy/ulegyria and } \\
\text { mild dysplastic features }\end{array}$ & $\begin{array}{l}\text { Abnormal MRI } \\
\text { with right } \\
\text { MCA infarct }\end{array}$ & Right & $\begin{array}{l}\text { Right functional } \\
\text { hemispherec- } \\
\text { tomy }\end{array}$ & 0 & 8 & 14 & 40 & $b$ & Left hemianopia & IA \\
\hline & K.Q. & $\mathrm{F}$ & $\begin{array}{l}\text { Medically intractable focal } \\
\text { epilepsy/mild increase in } \\
\text { white matter neurons } \\
\text { and reactive gliosis }\end{array}$ & Non-lesion MRI & Right & $\begin{array}{l}\text { Right anterior tem- } \\
\text { poral lobectomy } \\
\text { and hippocam- } \\
\text { pectomy }\end{array}$ & 13 & 15 & 16 & 76 & c & Full & IA \\
\hline
\end{tabular}

FCD, Focal cortical dysplasia; MCA, middle cerebral artery.

${ }^{a}$ Could not be reliably obtained because of language barrier.

${ }^{b}$ Assessment was done but did not include FSIQ-I.

Will be due for postoperative testing.

${ }^{d}$ For details of the Engel outcome scale, see Engel (1993).

view Board of Carnegie Mellon University and by the University of Pittsburgh (an interpreter assisted T.C.'s mother in completing the consent form).

\section{Experimental design and statistical analysis}

In this study, we adopted a matched case-control design to compare patient(s) (individual patient, 6 VOTC patients, or all 10 patients) to the corresponding control group using two main statistical approaches.
First, we compared each patient to the typically developing matched controls using modified $t$ tests (Crawford and Howell, 1998) in both behavioral and fMRI experiments. To further avoid the multiplecomparisons problem in fMRI, a false discovery rate (FDR) correction was used. Second, we compared (1) all 10 patients to the 10 matched controls, and (2) just the 6 VOTC patients to their matched controls to determine whether, as a group, the patients have atypical organization of high-level visual cortex. Given the limited number of data points, we 


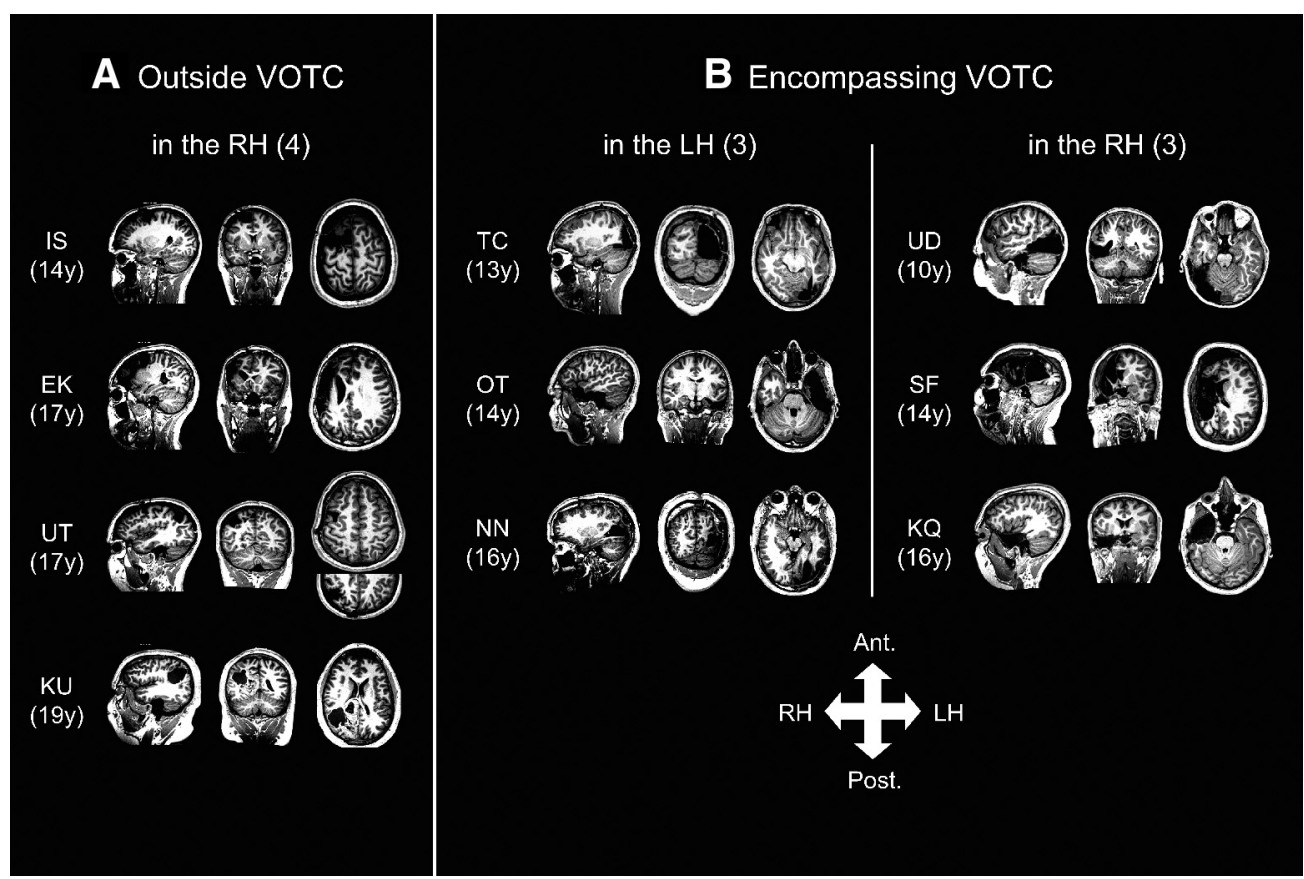

Figure 1. Postsurgical MRI showing the site and extent of the resection in each patient (age at scan in parenthesis). Resection in $\boldsymbol{A}$, four patients was outside the VOTC; $\boldsymbol{B}$, six patients, three $\mathbf{L H}$, and three RH resections, involved the VOTC.

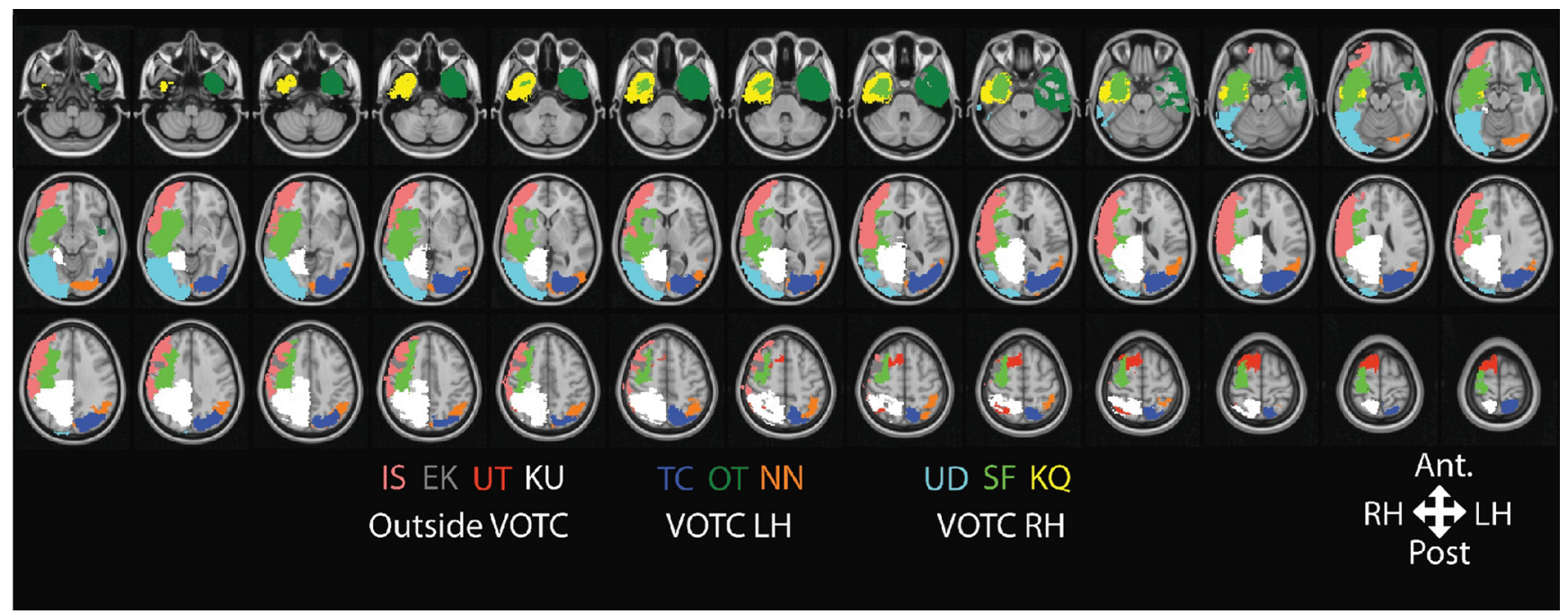

Figure 2. Overlay map constructed from the lesions of all 10 patients. Each color denotes the extent of the resection in a single patient (code for each patient is at the bottom of the figure; Table 1). The resections were hand-drawn in native space for each patient and transformed to MNI space for visualization purposes only.

used permutation analyses (Freud et al., 2017b; Rosenthal et al., 2017); participants were randomly assigned to one of two groups (group labels scrambled) and a two-sample $t$ test was performed. The same procedure was performed on the permuted groups 10,000 times in the analysis of the imaging data. This procedure generated the null distribution of the between-group $t$ scores for each region-of-interest (ROI). Finally, a $p$ value (FDR-corrected) was calculated for the comparison between the patients and the controls, based on the permuted null distribution. The permutations analyses yielded similar results when based on samples with or without replacement.

\section{Behavioral experiments}

Visual perception was assessed in all six VOTC patients and non-VOTC patient (E.K.), and matched controls using a 14 inch laptop. Viewing distance was $\sim 60 \mathrm{~cm}$.

\section{Global form perception}

Psychophysical thresholds were obtained from two separate tasks involving intermediate-level vision.

Contour integration. The contour integration task included two collinearity conditions (Hadad et al., 2010): target Gabor elements had either $\pm 20^{\circ}$ or $\pm 0^{\circ}$ collinearity, and participants pressed one of the two keys to indicate whether an embedded egg-like shape pointed rightward or leftward (Fig. $3 A$ ). Background elements were varied according to a 1-up (after a wrong response), 3-down (after 3 correct responses) staircase procedure, and the experiment continued until 10 reversals in the staircase occurred. A practice session ( 10 trials) preceded each version of the task and the experiment took $\sim 20 \mathrm{~min}$. The threshold score was calculated from the geometrical mean spacing of the final six reversals. The active display (containing Gabor elements) extended $\sim 17.6^{\circ}$ horizontally and $12.6^{\circ}$ vertically. 
Table 2. Patients' neuropsychological evaluation test performance before and after the surgery

\begin{tabular}{|c|c|c|c|c|c|c|c|c|}
\hline Group & Patient & Gender & Hemisphere & Detailed IQ measures & $\begin{array}{l}\text { Vision or visual motor } \\
\text { integration }\end{array}$ & $\begin{array}{l}\text { Memory \& } \\
\text { learning }\end{array}$ & Executive function & Academic skills/performance \\
\hline \multirow[t]{2}{*}{ Frontal } & I.S. & $\mathrm{F}$ & Right & $\begin{array}{l}\text { Presurgery: WISC-V: } 118 \\
\text { Postsurgery: WASI: } 99 \text { (full scale), } 100 \\
\text { (verbal), } 98 \text { (performance) WISC-V: } 102\end{array}$ & $\begin{array}{l}\text { Grooved pegboard: } \\
\text { average (dominant } \\
\text { hand) }\end{array}$ & Not done & DKEFS: average & WJ III ACH: age level \\
\hline & E.K. & M & Right & $\begin{array}{l}\text { Presurgery: not done } \\
\text { Postsurgery: not done }\end{array}$ & Not done & Not done & Not done & Not done \\
\hline \multirow[t]{2}{*}{ Parietal } & U.T. & $\mathrm{F}$ & Right & $\begin{array}{l}\text { Presurgery: WISC-V: } 90 \\
\text { Postsurgery: WISC-V: } 79\end{array}$ & $\begin{array}{l}\text { VMI-6: } 92 \text { (27th percen- } \\
\text { tile) Grooved peg- } \\
\text { board: average } \\
\text { (dominant hand) }\end{array}$ & Not done & Average & Not done \\
\hline & K.U. & M & Right & $\begin{array}{l}\text { Presurgery: N/A } \\
\text { Postsurgery: } 103\end{array}$ & Not done & Not done & Not done & Not done \\
\hline \multirow[t]{3}{*}{ Left VOTC } & T.C. ${ }^{a}$ & $\mathrm{~F}$ & Left & $\begin{array}{l}\text { Presurgery: WIAT III: 2nd percentile } \\
\text { Postsurgery: not done }\end{array}$ & Not done & Not done & Not done & $\begin{array}{l}\text { PPVT: 1st percentile }{ }^{a} \text { WIAT III: } \\
\text { Reading: 1st grade }{ }^{a} \text { Spelling: } \\
\text { 2nd grade }\end{array}$ \\
\hline & 0.T. & M & Left & $\begin{array}{l}\text { Presurgery: WASI: } 122 \text { (full scale), } 125 \\
\text { (verbal), } 114 \text { (performance) } \\
\text { Postsurgery: WASI: } 127 \text { (full scale) }\end{array}$ & $\begin{array}{l}\text { Grooved pegboard: } \\
\text { average (dominant } \\
\text { hand) }\end{array}$ & $\begin{array}{l}\text { CVLT-C: high } \\
\text { average } \\
\text { WRAML-2: } \\
\text { high } \\
\text { average }\end{array}$ & DKEFS: superior & $\begin{array}{l}\text { WJ III ACH: above age and grade } \\
\text { expectancy }\end{array}$ \\
\hline & N.N. & M & Left & $\begin{array}{l}\text { Presurgery: WASl: } 67 \text { (full scale), } 73 \text { (ver- } \\
\text { bal), } 64 \text { (performance) } \\
\text { Postsurgery: not done }\end{array}$ & Not done & Not done & Not done & Not done \\
\hline \multirow[t]{3}{*}{ Right VOTC } & U.D. & M & Right & $\begin{array}{l}\text { Presurgery: WASI: } 116 \text { (full scale) } 135 \\
\text { (verbal), } 97 \text { (performance) } \\
\text { Postsurgery: WASI: } 118 \text { (full scale), } 123 \\
\text { (verbal), } 108 \text { (performance) }\end{array}$ & $\begin{array}{l}\text { Grooved pegboard: } 50 \text { th } \\
\text { percentile (dominant } \\
\text { hand) }\end{array}$ & Not done & $\begin{array}{l}\text { Working memory } \\
\text { (from WISC-V): } \\
\text { Postsurgery: } 34 \text { th } \\
\text { percentile }\end{array}$ & $\begin{array}{l}\text { WJ III ACH: Reading: 63rd per- } \\
\text { centile Letter-Word: 67th } \\
\text { percentile Passage: } 56 \text { th } \\
\text { percentile Calculation: } 915 t \\
\text { percentile }\end{array}$ \\
\hline & S.F. & $\mathrm{F}$ & Right & $\begin{array}{l}\text { Presurgery: WASI: } 40 \text { (full scale), } 42 \text { (ver- } \\
\text { bal), } 43 \text { (performance) } \\
\text { Postsurgery: }\end{array}$ & Not done & Not done & Not done & Not done \\
\hline & K.Q. & $\mathrm{F}$ & Right & $\begin{array}{l}\text { Presurgery: WASI: } 76 \text { (full scale), 5th per- } \\
\text { centile but not reflect skills, 16th per- } \\
\text { centile (verbal), 3rd percentile } \\
\text { (perceptual reasoning) } \\
\text { Postsurgery: }\end{array}$ & Not done & Not done & Not done & Not done \\
\hline
\end{tabular}

CVLT-C, California Verbal Learning Test: Children's Version; D-KEFS, The Delis-Kaplan Executive Function System; Grooved Pegboard, Grooved Pegboard for Manipulation and Dexterity Testing; PPVT, Peabody Picture Vocabulary Test; VMI-6, Developmental Test of Visual Motor Integration, 6th Edition; WASI, Wechsler Abbreviated Scale of Intelligence; WIAT-III, Wechsler Individual Achievement Test, Third Edition; WISC-V, Wechsler Intelligence Scale for Children, Fifth Edition; WJ III ACH, The Woodcock-Johnson III Tests of Achievement; WRAML-2, Wide Range Assessment of Memory and Learning, Second Edition.

${ }^{a}$ Could not be reliably obtained due to language barrier.

${ }^{b}$ Assessment was done but did not include FSIQ-I.

Will be due for postoperative testing.

Glass patterns. Here, participants were instructed to press one of the two response keys to indicate which one of the two sequentially displayed Glass patterns had more concentric-"swirl" (Fig. 3B). We varied the percentage of signal dots (Lewis et al., 2002) using a 1-up (after incorrect response), 3-down (after 3 correct responses) adaptive staircase method to measure the $75 \%$ threshold. The staircase started at $95 \%$ signal and terminated after 10 reversals, and the threshold was measured from the geometric mean of the last six reversals. The practice session contained 10 trials and the experiment took $\sim 15 \mathrm{~min}$. Each Glass pattern was centrally presented and extended $\sim 8.57^{\circ}$ horizontally and $8.56^{\circ}$ vertically.

\section{Pattern recognition}

The integrity of high-level pattern recognition was explored using two tests, one for face and one for object recognition.

Face recognition. We used the Cambridge Face Memory Test for children (CFMT-C; Croydon et al., 2014; Fig. 3C) and followed the standard test instructions. Participants studied five faces and then, in subsequent trials, identified each "old" face from among new, distractor faces. The test was conducted using upright and inverted faces in separate blocks. There were 60 trials in each orientation consisting of 15 introductory trials, 25 trials without noise, and 20 trials with added noise. Performance was the percentage correct of all 60 trials, separately for the upright and inverted version. Each face was presented centrally, extending $\sim 3.4^{\circ}$ horizontally and $4.9^{\circ}$ vertically.

Object recognition. In this task (Fig. 3D; adapted from Gauthier et al., 1999), two objects were presented simultaneously, one above and one below the midline, for same/different discrimination. Each object subtended $\sim 7.3^{\circ}$ horizontally and $6.9^{\circ}$ vertically on the screen. The task consisted of 100 trials, 40 same and 60 different (20 per difference level), randomly intermixed. When the objects differed, they could differ at the basic (e.g., duck vs vehicle), subordinate (e.g., chair vs piano), or exemplar level (e.g., table1 vs table2), reflecting increasing perceptual similarity. The display remained on the screen until response, with one key indicating "same" and another "different". Instructions encouraged both speed and accuracy (and both were measured), and a 25-trial practice block familiarized the participant with the speeded task.

\section{fMRI experiments}

MRI setup

MRI data were acquired on a Siemens Verio 3T magnet at the Scientific Imaging and Brain Research Center at Carnegie Mellon University, using a 32-channel phased array head coil. Four controls with no prior MRI experience completed a practice session in a mock scanner, acclimating to the experimental conditions and minimizing head motion. All patients had been scanned previously at the UPMC Children's Hospital of Pittsburgh. Participants practiced the experimental tasks outside the scanner.

\section{Task and stimuli}

The visual presentations were generated using MATLAB (MathWorks) and Psychtoolbox (http://www.psychtoolbox.org). Images were back- 
A

$$
0^{\circ} \text { collinearity }
$$
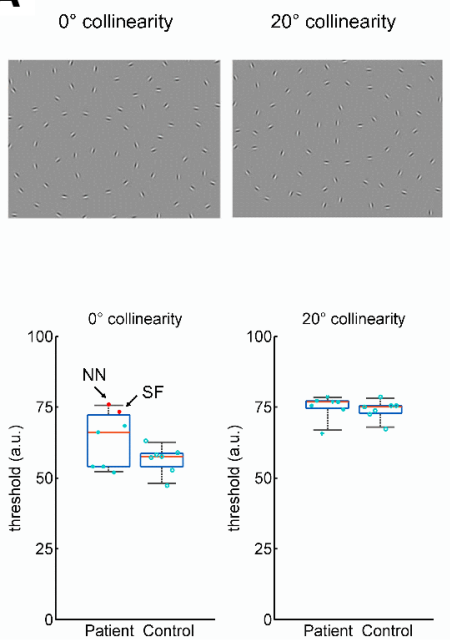

B
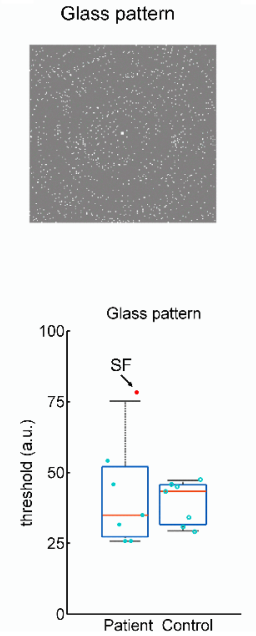

C

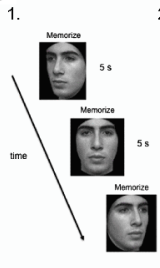

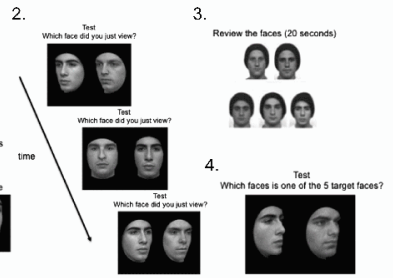
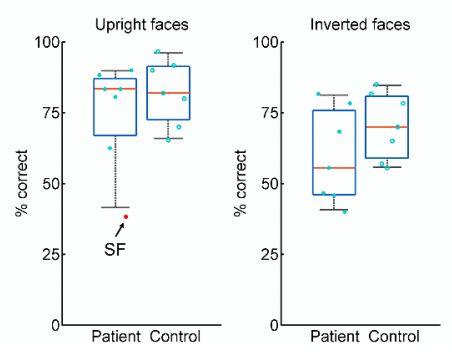
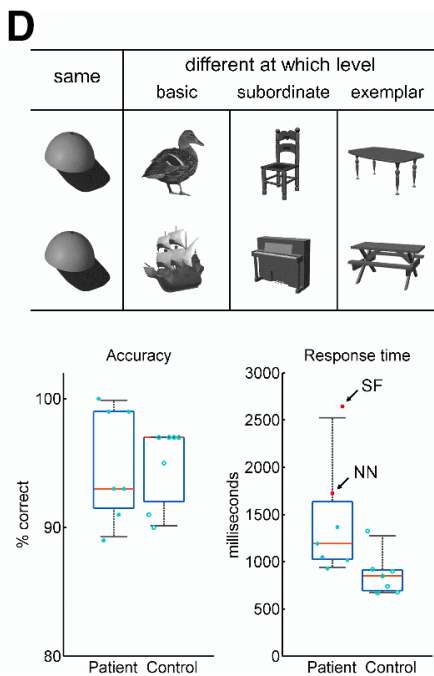

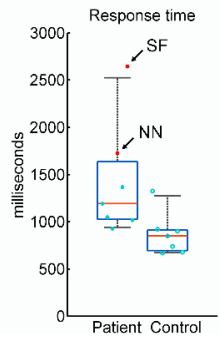

Figure 3. Experimental design and results of the behavioral experiments. In all panels, examples of stimuli are shown at the top and corresponding results are shown at the bottom. Boxplot represents the median (red line), the 25 and $75 \%$ quartiles (length of the blue box), the minimum and maximum values (black whiskers), and the value for each participant (patient, solid circle; control, empty circle). For visualization purposes, each circle in the boxplot was offset slightly and the sequence of dots (along the $x$-axis) was in accordance with the order of patients presented in Table 3. Individual red dots in the patient group denote significant deviation from the controls' performance using the Crawford modified $t$ tests. There were no outliers in the control group on any task. $A$, Contour integration (Hadad et al., 2010). Task: participants viewed a brief presentation and indicated the leftward or rightward pointing of the embedded "egg-like" shape. Results: patients and controls were found to have similar thresholds, except that the threshold in the $\pm 0^{\circ}$ collinearity condition in patients N.N. and S.F. was outside the control range. B, Glass pattern (Lewis et al., 2002). Task: participants pressed a button to indicate which of the two displays had a more concentric swirl. Results: all patients showed normal threshold except patient S.F. C, CFMT-C (Croydon et al., 2014). Task: participants were instructed to remember target faces and subsequently identify them among an array of distractor faces. Results: all patients showed normal face recognition abilities except patient S.F. D, 0bject recognition experiment (Gauthier et al., 1999). Task: participants made same/different discriminations on pairs of objects and pressed a "same" or "different" button to indicate their response. Results: patients and controls were found to have similar accuracy and RTs, excluding patients N.N. and S.F. who exhibited slower RTs.

projected onto a screen in the bore of the scanner (visual angle $=16^{\circ}$ ). A trigger pulse from the scanner synchronized the onset of the stimulus presentation to the beginning of the image acquisition. During the category localizer tasks, a central fixation dot remained on the screen to orient participants' fixation. Participants were instructed to maintain fixation and eye movement data were collected using an ASL eye tracker (Applied Science Laboratories). Analysis of eye positions confirmed that all patients maintained fixation within the $1.5^{\circ}$ of visual angle from the center of the screen during the task [excluding blinks, gaze deviation from the center: $1.02^{\circ} \pm .31^{\circ}$ (horizontally), $1.24^{\circ} \pm .36^{\circ}$ (vertically)].

Participants completed three runs of an fMRI category localizer task (Nestor et al., 2016; except patient N.N. and his control who completed 2 runs). The functional runs adopted a block design with stimuli from five categories (Fig. 4A): faces, houses, objects, scrambled objects, and words. Each run consisted of three repeats of each category ( 8 TRs, 16 images) in pseudorandom order with a fixation baseline (4 TRs) between all conditions. Thus, each run contained 15 categories and 16 fixation baselines and lasted 6 min $8 \mathrm{~s}$ (184 TRs). Participants indicated detection of an immediately repeating image (one-back task) via an MR compatible button glove using the right index finger. This response instruction was designed to engage participants maximally while keeping the task relatively easy for the children (overall accuracy: $95.2 \pm 3.6 \%$, no patient/ control group difference: $F_{(1,18)}=1.21, p=0.286$, one-way ANOVA).

\section{Structural MRI}

A high-resolution $\left(1 \mathrm{~mm}^{3}\right.$ isotropic voxels, 176 slices, acquisition matrix $=256 \times 256, \mathrm{TR}=2300 \mathrm{~ms}, \mathrm{TE}=1.97 \mathrm{~ms}$, inversion time $=900 \mathrm{~ms}$, flip angle $=9^{\circ}$, acceleration $/$ GRAPPA $=2$, scan time $=5 \min 21 \mathrm{~s}$ ) T1-weighted whole-brain image was acquired for each participant using a magnetization prepared rapid gradient echo imaging sequence for localization, coregistration, and surface reconstruction purposes.

\section{Functional MRI}

In six patients and matched controls, fMRI data were collected with a BOLD contrast-sensitive echoplanar imaging sequence $(\mathrm{TR}=2000 \mathrm{~ms}$, $\mathrm{TE}=30 \mathrm{~ms}$, voxel size $=2.5 \mathrm{~mm}^{3}$, interslice time $=79 \mathrm{~ms}$, flip angle $=$ $79^{\circ}$, acceleration/GRAPPA $=2,27$ slices). In the other four patients and matched controls, fMRI data with whole-brain coverage (69 slices) were collected with a multiband acceleration factor of 3 and voxel size $=2$ $\mathrm{mm}^{3}$ (all else equal to standard protocol). For all participants, slice prescriptions were AC-PC aligned.

\section{fMRI data analysis}

\section{Preprocessing}

fMRI raw data are available at https://doi.org/10.1184/R1/6856424.v1. Structural MRI and fMRI data were processed in BrainVoyager 2.8 (Brain Innovation), FSL 5.0 (FMRIB) and in-house MATLAB scripts. In patients N.N. and U.D., to reduce the variability of the noise in the time series (see Temporal signal-to-noise ratio equation), despiking of highmotion time points was performed using the ArtRepair toolbox (https:// cibsr.stanford.edu/tools/human-brain-project/artrepair-software.html) in Statistical Parametric Mapping (https://www.fil.ion.ucl.ac.uk/spm/).

Preprocessing of the anatomical MRI included brain extraction/skull stripping, intensity inhomogeneity correction, and AC-PC alignment. Given the variability in the extent and site of the lesions in the patients, there was no spatial normalization and analyses were conducted in native space. Functional data were 3D-motion corrected (trilinear/sinc interpolation), slice-time corrected, and temporally filtered (high-pass GLM Fourier $=2$ cycles). Functional runs were coregistered with the structural scan using boundary-based registration approach. To permit the multivariate analysis, no spatial smoothing was applied.

\section{Head motion}

During each run, for each participant, the head motion was calculated from the combination of three translation parameters (in millimeters) and three rotation parameters (in degrees) using the following equations:

$$
\begin{gathered}
\text { Total translation }=\sqrt{d(x)^{2}+d(y)^{2}+d(z)^{2}}, \\
\text { Total rotation }=\sqrt{r(x)^{2}+r(y)^{2}+r(z)^{2}} .
\end{gathered}
$$

The average head motion for patients was $0.49 \pm 0.21 \mathrm{~mm}$ (translation) and $0.52 \pm 0.28^{\circ}$ (rotation), and for controls was $0.53 \pm 0.25 \mathrm{~mm}$ (translation) and $0.47 \pm 0.27^{\circ}$ (rotation). See also Figure $6, A$ and $B$. 


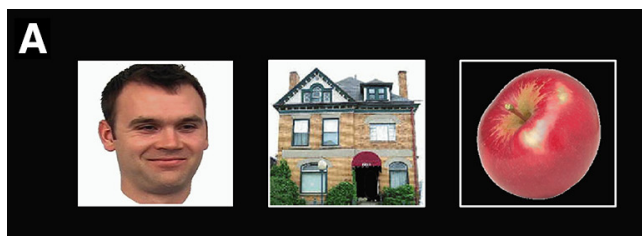

B

C

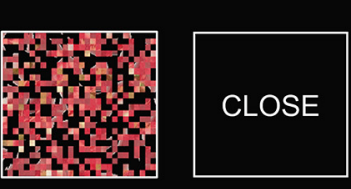

(

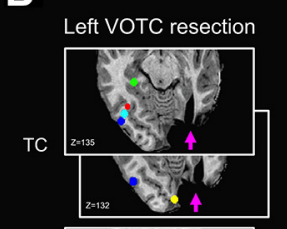

Right VOTC resection

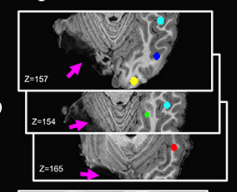

Left VOTC resection Face-House Word-Face

TC
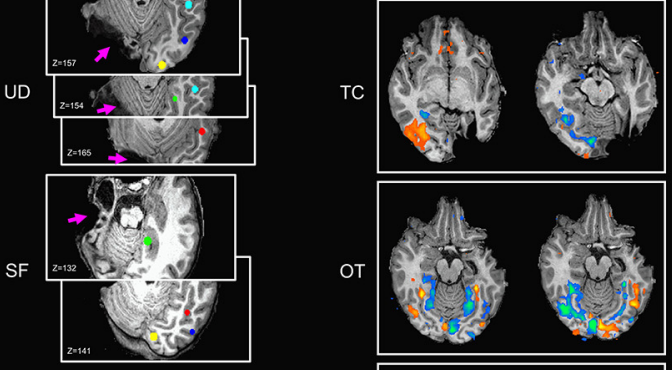

OT

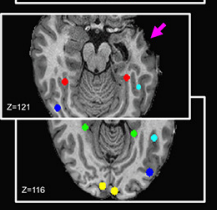

NN
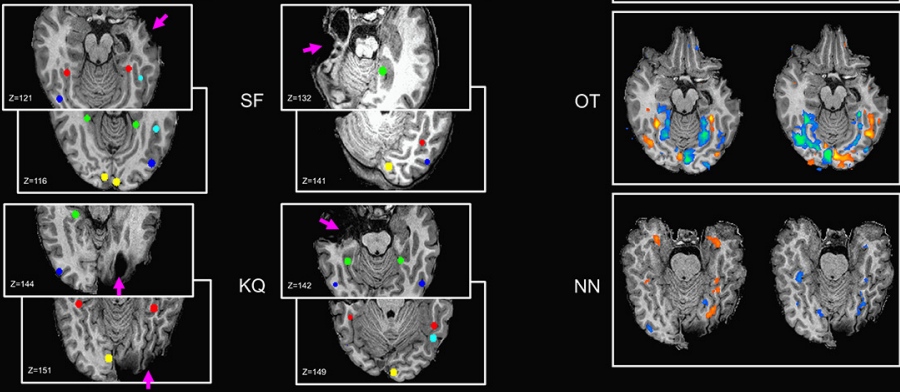

NN

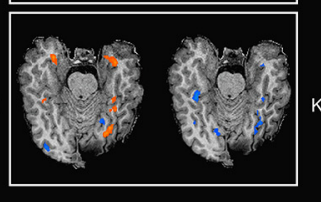

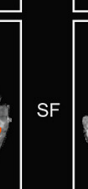

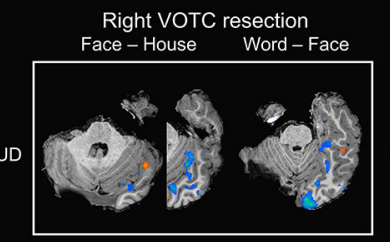

Resection outside VOTC
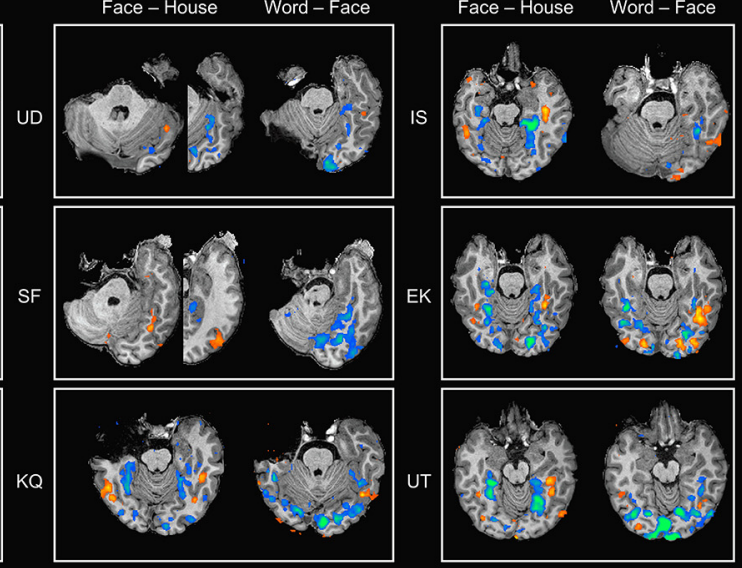

$p<.005$ in all the maps (uncorrected)

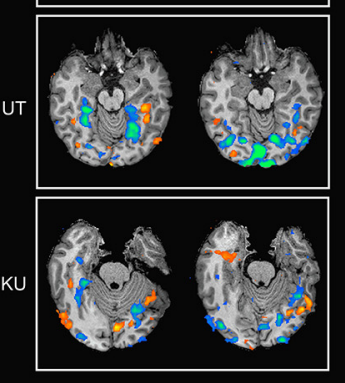

Figure 4. Category-selectivity and EVC activation in the patients. $\boldsymbol{A}$, Stimuli used in the fMRI category localizer experiment. $\boldsymbol{B}, A$ visualization of category-selective and EVC ROIs in each of the six VOTC patients. Pink arrows point to the site of the resection. Each colored sphere indicates one identifiable category-selective or EVC ROI (see color legend on the bottom left). The $z$ values at the bottom left corner on each axial slice denotes the position of that slice in the z- (inferior-superior) axis in native space. All ROls were defined in native space. C, Statistical maps of category-selective activation $(p<0.005)$ in each patient obtained from two representative contrasts: face-house, and word-face contrast.

\section{Temporal signal-to-noise ratio}

To ensure equivalent fMRI data quality across participants, we used temporal signal-to-noise ratio (tSNR) as an index of the temporal SNR for each voxel. To minimize the influence from signal dropout because of resection, we excluded those voxels in the lesion mask (Fig. 2) for tSNR calculation in each patient. For each run, tSNR was calculated as the mean signal of the fMRI time series divided by the SD of the noise in the time series: $\mathrm{SNR}_{\text {(temporal) }}=\mu_{\text {time series }} / \sigma_{\text {time series }}$.

\section{General linear model}

For each run, a standard general linear model (GLM) was performed. The regressor for each condition (faces, houses, objects, scrambled objects, and words) was defined as a boxcar function convolved with a canonical hemodynamic response function (Glover, 1999). To avoid overfitting, fixation conditions were not included.

\section{ROI definition}

To delineate both category-selective and EVC regions, a series of contrasts were used. In each participant, category-selective ROIs were defined as a sphere (radius: $7 \mathrm{~mm}$ ) centered on the peak voxel under each paired contrast (see second paragraph under ROI definition), with the difference score controlling for any differences in raw signal strength in each session (and ensuring the optimal response for each participant).

The fusiform face area (FFA) was defined as the region in the midfusiform gyrus with greater activation for faces compared with houses. The parahippocampal place area (PPA) was defined as the region in the anterior portion of the parahippocampal gyrus with greater activation for houses compared with faces. The lateral occipital complex (LOC) was defined as the region on the lateral surface of the occipital lobe with greater activation for intact objects compared with scrambled objects. The visual word form area (VWFA) was defined as a region in the left fusiform gyrus with greater activation for words than faces (except in T.C. who showed a remapping to the right VWFA). Finally, EVC was defined as a region in the posterior calcarine sulcus with greater activation for scrambled objects than fixation. For each participant, the sensitivity of each region to the preferred category was estimated by computing the $t$ value of the above contrast.

\section{The spatial relationship between ROIs}

To estimate the extent to which the spatial organization of the different ROIs was preserved in the patient group, we first extracted the native coordinates of all ROIs for each participant. Because we were unable to normalize the lesioned brains without further distortion, we quantified the spatial topography of ROIs in each participant by correlating (using a multivariate correlation, MATLAB function: corr2) the coordinates of all identifiable ROIs in each patient and in each control with the average coordinates obtained for the controls.

Note that a preliminarily analysis of each individual's coordinates in native space showed that the $z$ - (inferior-superior) axis was relatively stable across ROIs (patients' SD $=5.13$, controls' SD $=4.93$ ), whereas the $x$ - (medial-lateral; patients' $\mathrm{SD}=30$, controls' $\mathrm{SD}=34$ ), and $y$ (posterior-anterior; patients' SD $=21$, controls' SD $=19$ ) axes varied considerably between ROIs. Therefore, the correlational analysis was conducted on the $x$ - and $y$-axes.

\section{Representational similarity analysis}

To characterize the nature of the representations, representational similarity analysis (RSA; Kriegeskorte et al., 2008) was applied. Beta values were calculated separately for all voxels in each ROI and condition. Next, for each ROI, the Pearson correlation coefficient between all conditions was computed, and Fisher transformations was applied to permit the use of parametric statistics. Finally, for each ROI, we calculated the average correlation between the preferred category and all other categories: high correlations reflect less selective representations, whereas low correlations reflect more dissociable or unique representations of the preferred category. 
Table 3. Behavioral results of visual perceptual performance in all patients and age-matched controls

\begin{tabular}{|c|c|c|c|c|c|c|c|c|}
\hline \multirow[b]{3}{*}{ Patient } & \multirow[b]{3}{*}{ Gender } & \multicolumn{3}{|c|}{ Intermediate-level vision } & \multicolumn{4}{|l|}{ High-level vision } \\
\hline & & \multicolumn{2}{|l|}{ Contour integration } & \multirow{2}{*}{$\begin{array}{l}\text { Glass pattern } \\
\text { Threshold }\end{array}$} & \multicolumn{2}{|l|}{ CFMT-C } & \multicolumn{2}{|l|}{ Object matching } \\
\hline & & $\begin{array}{l}\text { Threshold } \\
\left( \pm 0^{\circ} \text { collinearity) }\right.\end{array}$ & $\begin{array}{l}\text { Threshold } \\
\left( \pm 20^{\circ} \text { collinearity) }\right.\end{array}$ & & $\begin{array}{l}\text { Upright } \\
\text { faces }\end{array}$ & $\begin{array}{l}\text { Inverted } \\
\text { faces }\end{array}$ & Accuracy & RT \\
\hline E.K. & M & 54.01 & 75.51 & 54.17 & $88.33 \%$ & $81.67 \%$ & $100.00 \%$ & 1192.12 \\
\hline T.C. & $\mathrm{F}$ & 66.12 & 77.27 & 45.83 & $83.33 \%$ & $46.67 \%$ & $89.00 \%$ & 1047.66 \\
\hline 0.T. & $M$ & 54.01 & 65.73 & 31.67 & $62.50 \%$ & $55.56 \%$ & $99.00 \%$ & 929.73 \\
\hline N.N. & $M$ & $75.95^{*}$ & 78.63 & 25.83 & $80.56 \%$ & $45.83 \%$ & $93.00 \%$ & $1726.1^{*}$ \\
\hline U.D. & M & 51.96 & 76.88 & 25.83 & $83.33 \%$ & $68.33 \%$ & $91.00 \%$ & 1366.96 \\
\hline S.F. & $\mathrm{F}$ & $73.36^{*}$ & 76.83 & $78.33^{*}$ & $38.33 \% *$ & $40.00 \%$ & $93.00 \%$ & $2644.63^{*}$ \\
\hline K.Q. & $\mathrm{F}$ & 68.45 & 74.21 & 35.00 & $90.00 \%$ & $78.33 \%$ & $99.00 \%$ & 1018.14 \\
\hline \multicolumn{2}{|c|}{ Patient average } & $63.41 \pm 9.97$ & $75.01 \pm 4.32$ & $42.38 \pm 18.97$ & $75.2 \pm 18.59 \%$ & $59.48 \pm 16.69 \%$ & $94.86 \pm 4.41 \%$ & $1417.91 \pm 603.96$ \\
\hline \multicolumn{2}{|c|}{ Control average } & $56.45 \pm 5.05$ & $74.04 \pm 3.53$ & $39.4 \pm 7.74$ & $88.22 \pm 11.55 \%$ & $70.36 \pm 11.79 \%$ & $94.86 \pm 3.08 \%$ & $869.03 \pm 225.65$ \\
\hline
\end{tabular}

*Significance at $p<0.05$.

\section{Results}

\section{Behavioral results}

\section{Global form perception}

In the contour integration task (Hadad et al., 2010; Fig. 3A), each patient's thresholds fell within the normal range in the $20^{\circ}$ misaligned condition (Crawford's modified $t$ test: all $t$ values $<$ 2.202 , all $p$ values $>0.070$, two-tailed). In the aligned condition, however, N.N. and S.F. (Fig. 3A, 2 red outliers) showed significantly poorer performance than controls (N.N.: $t_{(6)}=3.612, p=$ 0.011 ; S.F.: $t_{(6)}=3.132, p=0.020$, two-tailed, Crawford's modified $t$ test). Similarly, each patient's threshold for detecting the presence of a swirl pattern in Glass pattern stimuli (Lewis et al., 2002; Fig. 3B) was in the normal range except for S.F. (Fig. 3B, red outlier; Crawford's modified $t$ test: $t_{(6)}=4.705, p=0.003$, twotailed). For results for each patient, see Table 3.

The perception of Glass patterns is thought to be achieved by lateral connections in V1/V2 neurons (Smith et al., 2002, 2007) and contour integration is thought to tap into longer-range interactions in V1-V3 (Field et al., 1993). In particular, the preserved global form perception for the four VOTC patient with visual field defects (N.N., S.F., T.C., and U.D.) implicates the sole contribution of their spared EVC.

\section{Pattern recognition}

On the CFMT-C (Croydon et al., 2014; Fig. 3C), only S.F. was impaired (Fig. $3 C$, red outlier; Crawford's modified $t$ test: $t_{(6)}=$ $4.041, p=0.007$, two-tailed). For all other patients, performance fell within the normal range (all $t$ values $<2.083$, all $p$ values $>$ 0.082). On the object discrimination task (Gauthier et al., 1999), N.N. and S.F. (Fig. 3D, two red outliers) showed significantly poorer performance than the controls (mean RT, N.N.: 1726.1 $\mathrm{ms}, t_{(6)}=3.553, p=0.012$; S.F.: $2644.6 \mathrm{~ms}, t_{(6)}=7.360, p=$ 0.0009 , two-tailed, Crawford's modified $t$ test) although accuracy was normal. All other patients' performance fell within the normal range (Crawford's modified $t$ test: all $t$ values $<$ 2.064 , all $p$ values $>0.085$, two-tailed). For results for each patient, see Table 3 .

All patients except N.N. and S.F., the two patients with the lowest IQ and broadest cortical alteration presurgically, showed normal perceptual performance across a wide range of global form and category-specific tasks. Setting these two cases aside, the results indicate that, even in cases with extensive resection for example, a right posterior temporal and entire occipital lobectomy (U.D.), normal perceptual behavior is preserved.

\section{fMRI results}

Presence of category-selective ROIs

Before any fMRI analyses, we confirmed that there were no between-group differences in head motion (translation: $F_{(1,18)}=$ $0.17, p=0.685$; rotation: $F_{(1,18)}=0.20, p=0.658$, one-way ANOVA $)$ or $\operatorname{tSNR}\left(F_{(1,18)}=1.34, p=0.266\right.$, one-way ANOVA; Fig. 6A). Furthermore, no significant deviation was noted in any patient's tSNR compared with the control group (all $t$ values $<$ 1.377 , all $p$ values $>0.202$ ). Thus, any potential differences between patients and controls cannot be attributed to differences in data acquisition or quality.

Consistent with the reported topography of categoryselectivity in children (Golarai et al., 2007; Scherf et al., 2007) and adults (Martin, 2007; Grill-Spector and Weiner, 2014), the ROIs in the typically developing controls consisted of bilateral faceselective FFA (Kanwisher et al., 1997; Weiner et al., 2014); bilateral scene-selective PPA (Epstein and Kanwisher, 1998); bilateral object-selective LOC (Malach et al., 1995), and left-lateralized word-selective VWFA (Cohen et al., 2000). In 9 of 10 controls, all 9 ROIs (bilateral: EVC, FFA, LOC, PPA; unilateral: VWFA) were identified. In the remaining control, the left FFA could not be defined and it is not unusual for the left FFA to be absent in some individuals (Kanwisher et al., 1997). That we were able to uncover robust category-selectivity at both the group and individual levels in the controls attests to the sensitivity of the experimental methods.

Our first analysis examined whether category-selective ROIs and EVC activations could be identified in the patients. In the four patients with resections outside the VOTC (Fig. 1A), unsurprisingly, all nine ROIs were successfully identified (Fig. $5 A$, four top rows, filled rectangles). Of the six patients with VOTC resections (Figs. 1B, $4 B$ ), four (N.N., S.F., T.C., and U.D.) had posterior and two (K.Q. and O.T.) had anterior resections. For the posterior resection cases, when the resected tissue overlapped with the predicted location of the ROI, no preferred category activation was found in the affected hemisphere but the ROIs could be defined in the preserved hemisphere (Figs. 4B, 5A). For the two patients with anterior resections, all nine ROIs were present (Figs. $4 B, 5 A$ ). For examples of category-selective activations in each patient, see Figure $4, B$ and $C$.

There were, however, some individual differences. T.C., whose resection partially involved the typical left VWFA, showed a right VWFA activation, the only instance of explicit remapping to the structurally intact hemisphere (Fig. $4 B$, cyan sphere in T.C.'s RH, Fig. $5 A$, empty square, $C$, cyan arrow). 
A

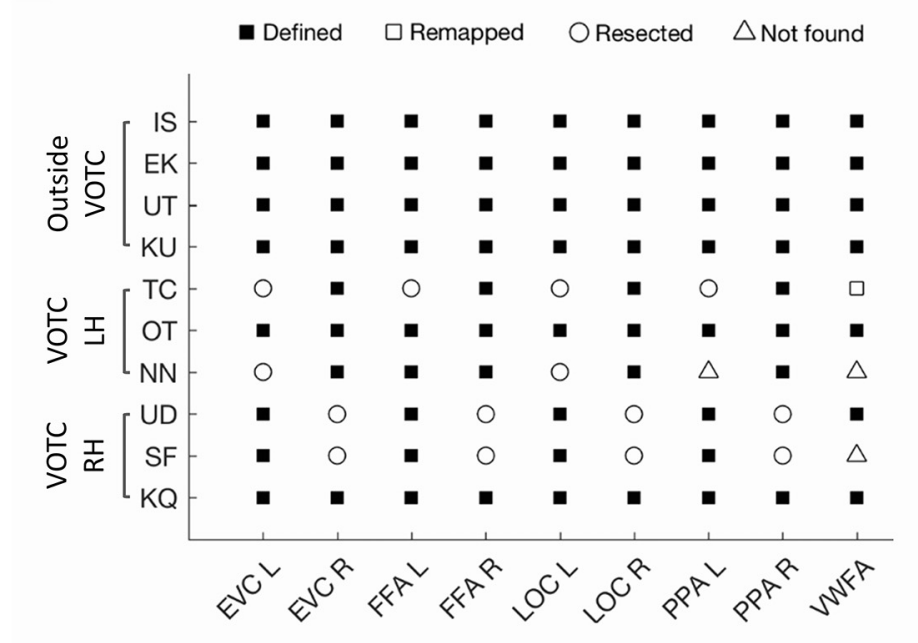

B

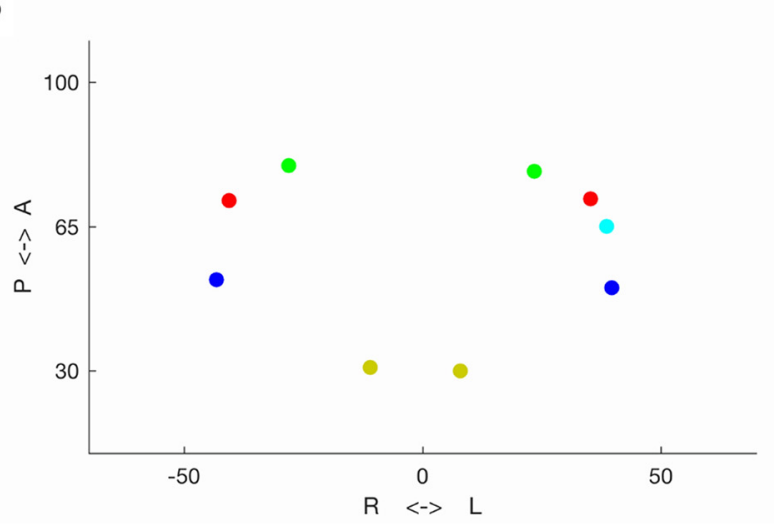

C
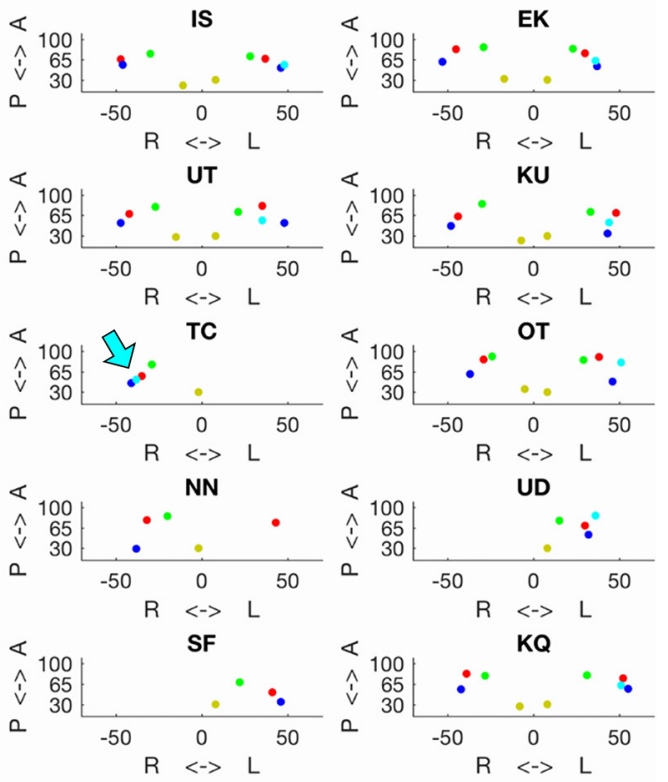

D

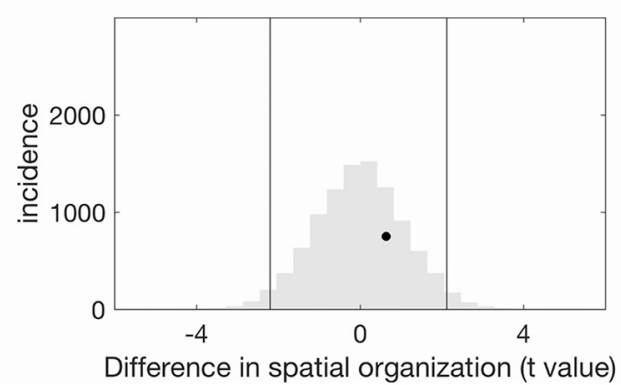

Figure 5. Spatial organization of category-selective ROls in patients and controls. $\boldsymbol{A}$, Category-selective and EVC ROIs defined in each patient. Symbol: ROI(s) that were defined (filled square) or remapped (empty square), or could not be defined because of resection (empty circle) or not found (empty triangle). $\boldsymbol{B}$, Visualization of the average spatial distribution of category-selective ROls in the controls. $x$-axis: coordinates in the medial-lateral direction in each hemisphere; $y$-axis: coordinates in the anterior-posterior direction. $\boldsymbol{C}$, Visualization of the spatial distribution of categoryselective ROIs in each patient. $x$-axis: coordinates in the medial-lateral direction in each hemisphere; $y$-axis: coordinates in the anterior-posterior direction. The cyan arrow (patient T.C.) indicates the location of the VWFA that was remapped to the RH. D, A permutation approach showed that the $t$ score of difference in the spatial organization between the VOTC patients and their matched controls (black dot) was within the null distribution of the between-group $t$ scores (gray histogram).

The immediate question that arises is whether T.C.'s crosslocalization of the VWFA was coupled to a shift in language dominance to the LH given that the VWFA is usually colocalized with areas critical for language (Devlin et al., 2006; Cai et al., 2008; Price and Devlin, 2011; Van der Haegen et al., 2012). The usual coupling of spoken and written language areas appears not to hold in T.C. as her presurgical clinical fMRI scans localized language to the LH with activation of the left pSTG (Wernicke) and left inferior frontal (Broca) region in languagerelated tasks (verb generation, stories, and synonyms generation). Also, because her resection did not impinge on her LH language areas, there is no particular pressure for language to be remapped interhemispherically.

Indeed, a similar atypical spoken and written language dissociation has been previously reported in an 11-year-old girl who underwent a left occipitotemporal resection at the age of 4 years (Cohen et al., 2004). As with T.C., her VWFA was uncovered in the RH but language lateralization was evident in the LH. In both T.C. and this other patient, it appears that speech and language emerged in the LH presurgically and before the acquisition of reading. Orthographic sensitivity in reading then emerged post- surgically (note that T.C.'s surgery was at age 13 years but seizures began at age 7 years; Table 1). The absence of interhemispheric transfer of language (and the transfer of the VWFA to the RH) in these two cases is consistent with a further previous finding in which only approximately one-third of cases showed transfer of language regions to the $\mathrm{RH}$ after a resection of the $\mathrm{LH}$ (Pahs et al., 2013).

There was no evidence of word-selectivity in S.F. (right VOTC resection) or in N.N. (left VOTC resection), perhaps consistent with their lower IQ scores (Table 1) and poor reading abilities. In addition, N.N. did not exhibit preferred activation for houses and its absence might result either from the posterior lesion disrupting low-level input to the PPA, from reduced statistical power (only 2 runs were available for this patient) or from the fact that some ROIs are simply not present even in normal observers. Importantly, however, in all six VOTC patients, the ROIs in the spared, contralesional hemisphere were successfully identified.

In sum, a resection of the VOTC, either right or left, did not obviously impair the category-selectivity of the contralesional hemisphere, and, with one exception (right VWFA in T.C.), the 
resected regions were not remapped to a different cortical location. In two cases, S.F. and N.N., the two individuals with lowest IQ scores and broadest cortical atypicality presurgically, the VWFA could not be identified and, for N.N., this was also true for the PPA. The following analyses were designed to scrutinize further the topography and functional properties of the identified ROIs.

\section{The spatial topography of category-selectivity}

This analysis determined whether the spatial arrangement of category-selective regions in the patients obeys the same spatial organization as the controls. This was achieved by measuring the pairwise correlation between the native coordinates of all identifiable ROIs in each patient and in each control with the average coordinates of the controls (see Materials and Methods).

As visualized in Figures 5, $B$ and $C$, both groups exhibited highly reliable spatial organization (mean $R_{\text {patients }}=0.980$; mean $\left.R_{\text {controls }}=0.985\right)$ that largely obeyed the established mediallateral organization (EVC-PPA-FFA-VWFA/LOC; Grill-Spector and Malach, 2004; Martin, 2007). Next, a series of Crawford modified $t$ tests revealed that 9 of 10 patients evinced spatial organization that was not differentiable from the controls (resected regions excluded from the analysis; all $t$ values $<1.35, p_{\mathrm{FDR}}$ $>0.25)$. The only exception was T.C. whose reduced correlation to the average spatial organization was likely the outcome of the reorganization of the VWFA to the $\mathrm{RH}\left(t_{(9)}=2.99, p=0.007\right)$, although this did not survive FDR correction $(p=0.07)$. Using a permutation approach (Freud et al., 2017b; Rosenthal et al., 2017), the spatial organization of ROIs in the two groups did not differ $(p=0.63)$, and this also held even when just the VOTC patients $(n=6)$ were compared directly against their tightly matched control group $(n=6 ; p=0.73$; Fig. $5 D)$.

These results indicate that the ROIs could be successfully identified in most patients with cortical resection, and that the spatial topography of the identified ROIs was preserved in these patients, independent of resection site or side. Next, we evaluated the functional properties of the ROIs in the patients and control. We first used univariate analysis to evaluate the magnitude of selectivity and then conducted multivariate analyses on the representational structure of the higher-order visual processing.

\section{Univariate analysis: the magnitude of category-selectivity}

The magnitude of category-selective responses for each ROI was derived by calculating the selectivity ( $t$ value) for each category based on the paired contrast between the preferred and nonpreferred categories (see Materials and Methods). First, singlecase comparisons revealed that all patients, across all defined ROIs, had normal magnitudes of category-selectivity (Crawford's modified $t$ test: all $t$ values $<2.22, p_{\text {FDR }}$ values $>0.25$, two-tailed; Fig. 6B).

Next, group-level analyses were conducted using a permutation approach (see Materials and Methods). The $t$ score of difference in the magnitude of selectivity was compared against the null-distribution of the between-group $t$ scores (Fig. 6C, gray histogram). When all 10 patients and controls were included, across all ROIs, there was no difference in visual selectivity between patients and controls $\left(p_{\mathrm{FDR}}>0.5\right)$, and this also held true when only the six VOTC patients and their matched controls were included in the analysis $\left(p_{\mathrm{FDR}}>0.5\right.$; Fig. $\left.6 C\right)$.

Together, the single-case and group-level analyses of the univariate category-selectivity and EVC activations revealed that the functional organization and sensitivity of the VOTC to different visual inputs was preserved even in those individuals with cortical resections encompassing the VOTC (in either $\mathrm{LH}$ or $\mathrm{RH}$ ).

\section{Multivariate analysis: representational structure of higher- order visual processing}

The above univariate analyses explored the magnitude of activation in each ROI but these findings are insensitive to the pattern of fMRI activation across all voxels within an ROI. Previous investigations have demonstrated the usefulness of multivariate approaches for uncovering the underlying neural representations of category-selective ROIs (Haxby et al., 2001; Bracci and Op de Beeck, 2016) even under a block-design experiment such as that used here (Freud et al., 2017a). To compare the representational basis of the different category-selective ROIs, we applied RSA to characterize the multivariate response patterns and strength of similarities among response patterns between preferred and nonpreferred categories for the patients and controls (Fig. 7A; see Materials and Methods).

Single-case analysis revealed that in all ROIs, with one exception (VWFA), there were no differences between patients and controls $\left(p_{\mathrm{FDR}}>0.15\right.$; Fig. $7 B$ ). In the VWFA, two patients showed a higher correlation between words and non-word categories than controls (K.U.: $t_{(9)}=2.44, p=0.037$; T.C.: $t_{(9)}=2.87$, $p=0.019$; Figure $7 B$, red dots), although for neither case did this result survive FDR correction $\left(p_{\mathrm{FDR}}=0.09\right)$. In T.C., the less dissociable representation might result from the remapping of the VWFA to the RH (Figs. $4 B, 5 C$ ).

At the group level, across all ROIs, the representational similarity between preferred and non-preferred categories, was similar when all patients $(n=10)$ and controls $(n=10)$ were included in the permutation analysis (all adjusted $p$ values $>0.2$ ) and, again, this was also true when the analysis was restricted to the VOTC patients and their matched-controls $\left(p_{\mathrm{FDR}}>0.12\right.$; Fig. 7C).

The analysis conducted above compared the patients' ROIs to the matched hemisphere of the controls; for example, the left (and only) FFA in the patients was compared with the LH of the controls. Because it remained a possibility that the unilateral ROIs in the preserved hemisphere might be different in the patients than the standardly preferred regions in controls (e.g., the right FFA in normal observers typically shows greater face selectivity than the left FFA), we also conducted the same RSA comparing the similarity of the unilateral ROI in the patients with that of the opposite hemisphere in the controls; for example, the left (and only) FFA in the patients was compared with the right FFA of the controls. This analysis was conducted on the three-bilateral category-selective ROIs (FFA, LOC, PPA). The results replicated those of the ipsilateral comparisons: the representational structure of the patients' ROIs was similar to that of the controls' contralateral ROIs $\left(p_{\mathrm{FDR}}>0.2\right)$.

In sum, we were unable to identify 17 of 90 ROIs in total. We could not identify 14 ROIs in regions that overlapped resected areas in the VOTC patients and a further 3 ROIs could not be defined in the preserved regions (VWFA in N.N. and S.F., and left PPA in N.N.). Among the remaining 73 ROIs, we observed largely typical spatial topography, normal magnitude of selectivity, and equivalent representational structures in the patients (albeit with VWFA remapped to the RH in patient T.C.). Remarkably, these results applied even to most, although not all, patients with large cortical resections or resections encompassing most of unilateral VOTC. There was little evidence of remapping to another region in the resected hemisphere or to the structurally intact hemisphere. Furthermore, the repre- 
A

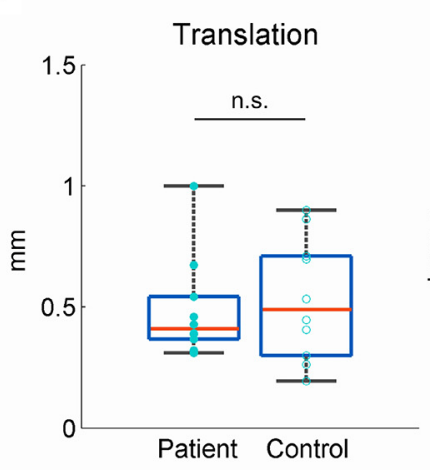

B

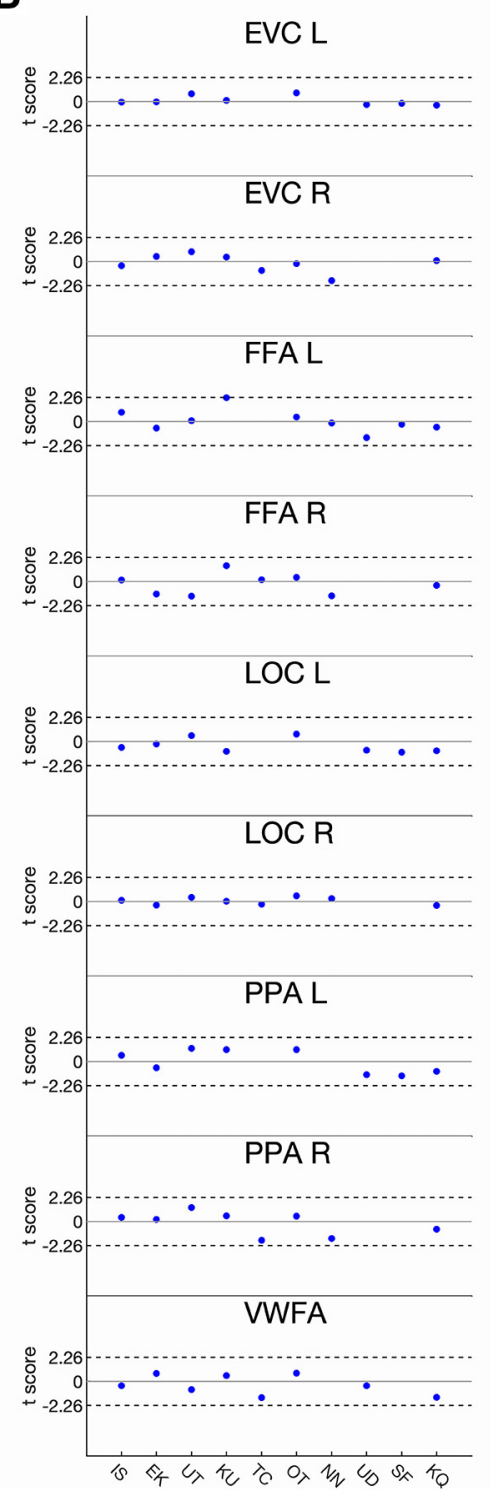

\section{Rotation}

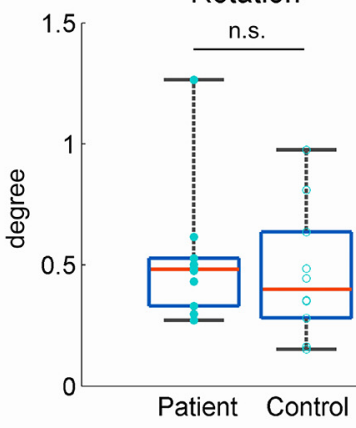

tSNR

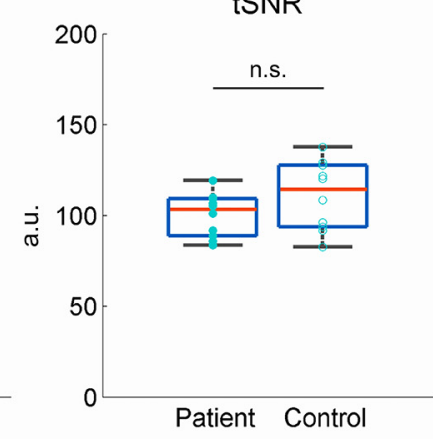

C

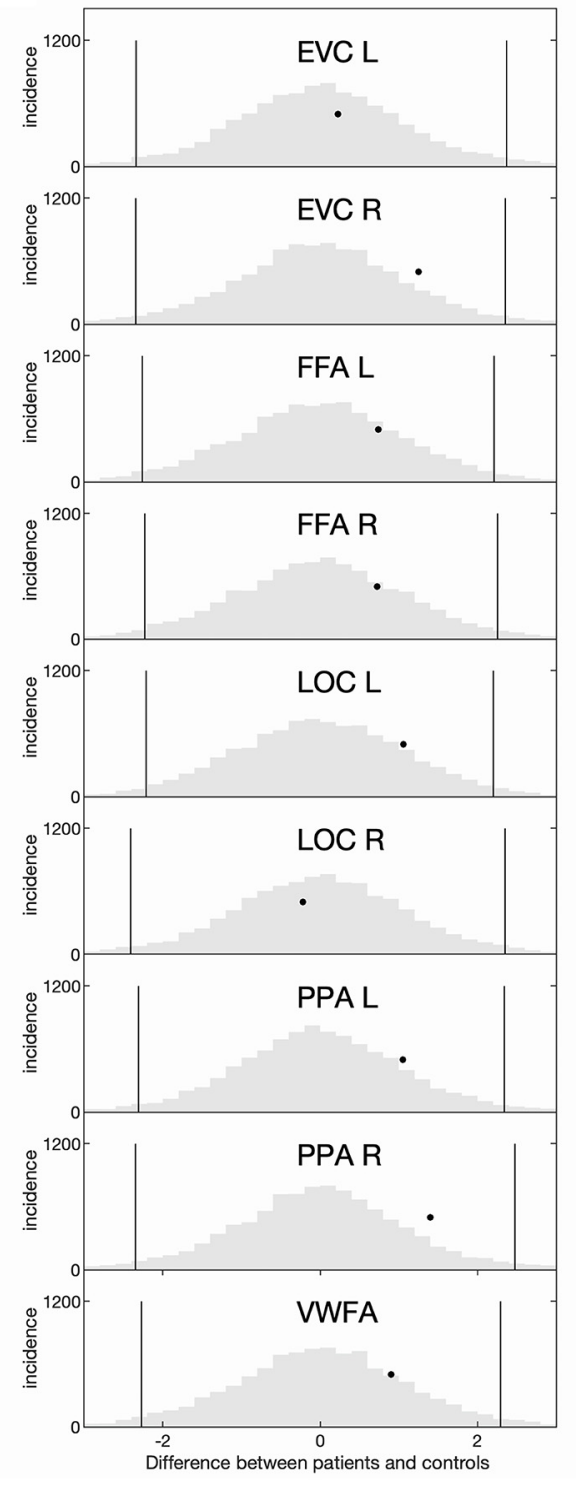

Figure 6. The quality of the scan and the magnitude of category-selective responses in patients and controls. $A$, Quality of the scan: the amount of translation (in millimeters), rotation (in degrees), and tSNR (in arbitrary units) did not differ significantly between patients and controls. Boxplot represents the median (red line), the 25 and $75 \%$ quartiles (length of the blue box), the minimum and maximum values (black whiskers), and the value for each participant (patient, solid circle; control, empty circle). B, Single-case comparisons: (rawford's $t$ tests show that the magnitude of category-selectivity and EVC activation in each patient was within the control range. $C$, Group-level analyses: a permutation approach compares the $t$ score of difference in the magnitude of selectivity between the VOTC patients and their matched controls (black dot) against the null distribution of the between-group $t$ scores (gray histogram). n.s. = not significant. 
A

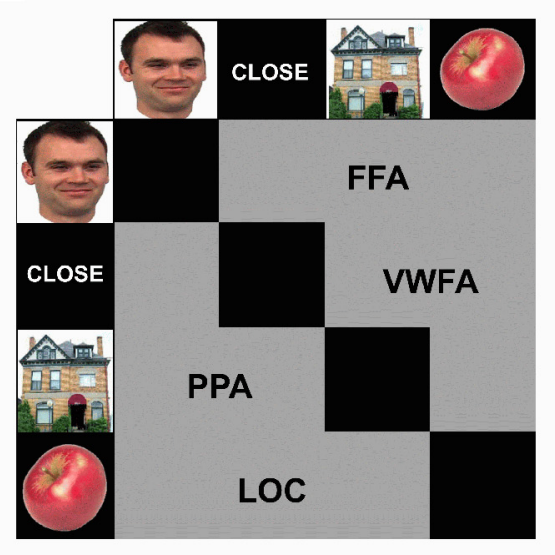

B

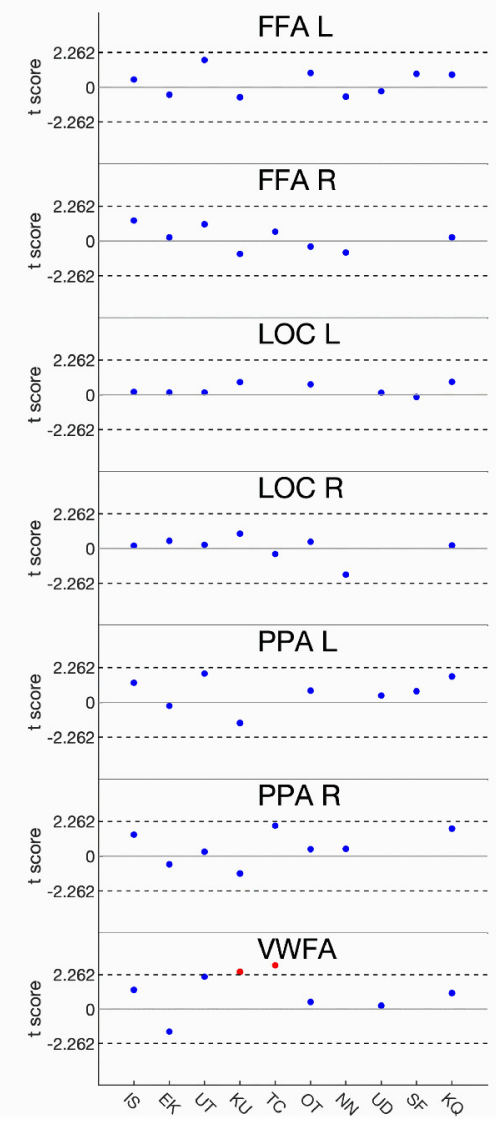

C

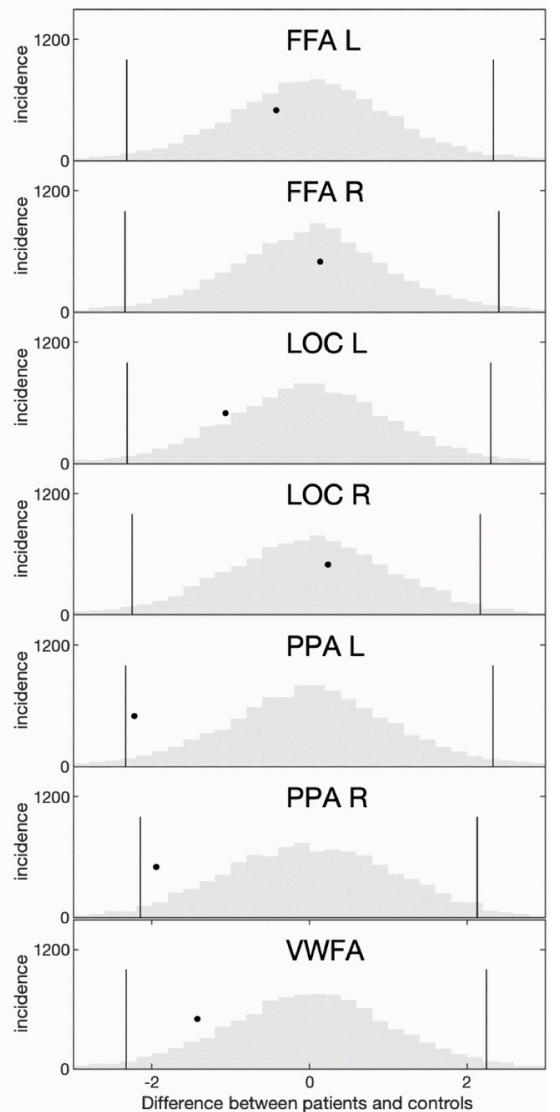

Figure 7. Representational similarity analysis of category-selective responses in patients and controls. $\boldsymbol{A}$, Schematic representational dissimilarity matrix illustrating the preferred category (black) and the non-preferred category (gray) for each ROI. B, Single-case comparisons: Crawford's $t$ tests showing that the representational similarity in each patient was within the control range except patients K.U. and T.C. in VWFA (although neither survived FDR correction). C, Group-level analyses: a permutation approach compares the tscore of difference in representational similarity between the VOTC patients and their matched controls (black dot) against the null distribution of the between-group $t$ scores (gray histogram).

sentational structure in the preserved hemisphere (even in VOTC cases) mirrored that of controls (both in the matched and in the opposite hemispheres).

\section{Discussion}

Studies of postsurgical outcome in children with pharmacoresistant epilepsy have provided valuable insights into neural plasticity and the functional restitution of behavior. The current study explored the neural and behavioral outcomes of 10 children or adolescents who had undergone unilateral cortical resection to address questions concerning the stability versus plasticity of the category-selective maps in visual cortex, possible alterations in perceptual behavior, and their relationship to the cortical maps, and factors that might account for differential postsurgical outcomes.

Independent of whether or not the resection included the VOTC, and independent of the hemisphere affected, there were, with just two exceptions, (1) normal intermediate vision and high-level face and object recognition; (2) normal neural category-selectivity in both magnitude and spatial distribution; and (3) normal representational structure in category-selective regions, as revealed by multivariate analyses. Of the two exceptions, the first was in patient T.C. in whom the VWFA was uncovered in the right homologous region (and neither the category-selectivity of this region nor its multivariate status differed from controls). The second exception was that the pattern of normal behavior and preserved neural profile was not evident in either S.F. (likely the largest resection) or N.N. (with polymicrogria resulting in a very different anatomical profile), both of whom had the lowest presurgical cognitive status.

This seeming early equipotentiality (in the majority of the cases) contrasts with the profound largely immutable perceptual deficits and absence of compensation in the adult brain following a unilateral lesion to VOTC; damage to the right temporal or occipital lobe in adulthood results in an impairment in face recognition that persists over long periods of time and perhaps over the entire lifetime (Busigny et al., 2010; Barton and Corrow, 2016; Weiner et al., 2016).

\section{Sufficiency of a single hemisphere for visual function}

The findings revealed the apparent sufficiency of a single hemisphere for most visual functions and category-selective topographic maps. With the single exception of the right VWFA in patient T.C., there was neither remapping of ROIs to spared cortical regions in the affected hemisphere nor to the spared hemisphere interhemispherically. Moreover, there were no apparent differences between the representational structures of the ROIs in the patients' single, structurally preserved hemisphere and either hemisphere of the control participants. Instead, the evidence argues against marked rearrangement of category-selectivity or recruitment of compensatory cortical regions in the visual system and indicates that, at least in the case of relatively early-onset 
epilepsy, in contrast to an acute lesion or late-onset epilepsy, a single VOTC, either left or right, suffices for the emergence of normal intermediate vision and pattern recognition.

Together, these findings argue for both plasticity and stability; plasticity is most clearly observed as in the case of atypical hemispheric manifestation of the VWFA. However, stability also is evident in that in most of the cases, the existing topography, selectivity, and representational basis of the structurally preserved hemisphere, which does not differ from either hemisphere of the controls, appears to suffice for the support for normal visuoperceptual behaviors. Whether the neural representations of the single preserved hemisphere are entirely normal still remains to be demonstrated, but the analyses included here indicate that, at least to a first-order approximation, this appears to be the case. Another example of stability or perhaps, in this case, immutability, is that, in the four patients with a resection encompassing the EVC, there was no remapping of the blind field to the spared EVC (Table 1). Presumably, the in situ wiring of the subcortical and cortical projections from the eye is stable and does not permit obvious plasticity unless the damage occurs prenatally or perhaps perinatally (for examples in the literature of ipsilateral visual field mapping, see Liu and Behrmann, 2017). Instead, it appears that only genetic manipulations or changes to the thalamic innervation, which presumably are only possible during neurodevelopment, yield large deviations from a stereotypical retinotopic map (Cang et al., 2005, 2008). Because there are insufficient cases, included either here or in the literature at large, that definitively indicate when and how plasticity versus stability might hold (for detailed presentation of existing cases, see Liu and Behrmann, 2017), future studies will shed further light on the plasticity-stability question.

\section{The critical role of experience}

The discussion thus far has focused on the possible mechanisms that support the positive functional outcomes. However, not all cases evince a positive outcome and understanding what factors might help determine prognosis is important theoretically and clinically. One factor concerns the presence of other visual deficits; for example, elementary visual deficits such as esotropia, amblyopia, reduced acuity, and visual field abnormalities. These accompanying visual deficits likely result in deprivation of normal experience and input, which may hamper a normal outcome, as in the case of Adam who never recovered the ability to recognize faces (Farah et al., 2000). A similar persistent impairment in face perception is present even in children with transient cataracts who, even without a cortical lesion, have long-lasting deficits in face and holistic processing (Le Grand et al., 2001, 2003, 2004; Lewis and Maurer, 2005).

The contribution of experience in fashioning categoryselective maps (and its absence when visual input is aberrant) is consistent with the emergent topography in VOTC that is established over the course of development or experience. Although neural category selectivity has been observed for different visual categories very early in life (Otsuka et al., 2007; Deen et al., 2017; Emberson et al., 2017; Barttfeld et al., 2018), this early selectivity is typically immature and not adult-like. For example, the left VWFA is weakly specified before the acquisition of literacy and there is ongoing refinement of word-selectivity over time (Saygin et al., 2016; Dehaene-Lambertz et al., 2018). The same holds for face-selectivity in that the early activation profiles in children is somewhat immature and then, with experience, this becomes well tuned in adults (Scherf et al., 2007, 2011; Golarai et al., 2010). Whether the mature pattern of cortical mapping results solely from experience-based tuning or, additionally, from brain maturation more generally is unclear as these are usually confounded. Based on data from monkeys raised without exposure to faces, however, experience clearly plays a critical role and deprivation of input has catastrophic effects on the development of category-selectivity: monkeys raised under these conditions had normal retinotopic organization, which appears to be established early in life, and developed cortical clusters selective for other visual categories, but not for the category of faces (Bi et al., 2016; Arcaro et al., 2017; but see Sugita, 2008).

\section{The role of other factors in determining prognosis}

Aside from the critical role of experience for configuring category-selectivity, a number of other factors may play a role in shaping the outcome. One well known heuristic is that the earlier the lesion, the greater the probability of recovery. Although demarcating the upper age bound beyond which recovery is not yet possible, the current study reveals that there is normality of behavior and neural profile in individuals whose neurological disorder manifests by $\sim 13$ years of age (and surgery by 15 years of age). Similarly, extensive training of symbol recognition in nonhuman primates leads to the development of symbol-selective clusters but only in juvenile and not in adult animals (Srihasam et al., 2014) and, in humans, adults who acquired literacy in adulthood evinced reduced word-selectivity in VOTC compared with those who gained literacy in childhood (Dehaene et al., 2015). There is currently much debate about the possibility of extending the critical or sensitive period of acquisition of various perceptual and cognitive processes both through behavioral intervention (Bavelier et al., 2010) and molecular mechanisms (Sigal et al., 2019), in general, especially in the context of the visual system (Hensch, 2005, 2016; Syken et al., 2006), but much research remains to be done in this regard.

A further factor and one that emerged in the present study concerns presurgical profile: the two patients with lower IQ scores showed neither normal perceptual function nor normal neural profile. We were unable to discern whether the relatively lower IQ status or impaired perceptual abilities per se account for their altered profile. Moreover, most perceptual tasks, including those adopted here, have some additional cognitive components such as attention, working memory, and sensory-motor processing speed, any of which might explain their poorer performance.

Last, etiology may play a role in prognosis: pediatric patients with more acute etiologies (e.g., stroke) do not always evince the same recovery as those with more chronic etiology (e.g., tumor; Liu and Behrmann, 2017) and the different timing afforded by more acute versus chronic causes may permit different patterns of reorganization. Specifically, patients with early-onset epilepsy who only come to surgery after a relatively long period may well have some degree of reorganization before surgery. Given that the tissue in and around an epileptogenic focus, as well as more remote tissue, may be dysfunctional before surgery, normal topography and selectivity of ROIs in these 10 patients may begin (and perhaps even be complete) before surgery (Kamm et al., 2018). Comparing presurgical and postsurgical profiles of cases such as those described here will help address this question, and longitudinal monitoring of the cases will shed further light on the timing of change.

\section{Conclusion and further considerations}

Importantly and puzzling in light of the current findings, not all disorders of visuoperceptual function and structure are resolved even if the problem manifests early in life; neurodevelopmental 
disorders such as developmental dyslexia and congenital prosopagnosia, the difficulty mastering word and face recognition, respectively, can persist from childhood through adulthood and can be somewhat immutable even with intervention. We are thus left with a conundrum: whereas a single hemisphere suffices for normal visual category-selective function in the pediatric resection cases, the presence of two hemispheres in those cases with atypical development does not guarantee normal acquisition of word or face recognition (Geskin and Behrmann, 2018). One possible explanation is that, in the neurodevelopmental cases, the underlying etiology, for example, the compromised white matter tracts (Thomas et al., 2009; Yeatman et al., 2012), are still in place and the atypical system continues to mediate visual computations, albeit detrimentally. In the VOTC resection cases, however, the dysfunctional properties of the epileptogenic tissue (and perhaps also the removal of abnormal cortical tissue) may release the preserved hemisphere to undergo normal category-selective differentiation, permitting intact behavioral functions.

Both the behavioral and neural investigations described here are, to our knowledge, the most detailed characterization of the status of visual category-selective structure and function in children with cortical resection. Needless to say, the different epileptic pathologies, the varied side and sites of resection, the varied ages at surgery and at testing and the varied level of presurgical intellectual function all contrive to reduce experimental control in studies such as this one. Nevertheless, given that "nature's experiments" elude such control, the general findings and principles derived confirm that the profile of normality is largely replicable across a series of cases. Indeed, the present crosssectional design has enabled us to reach conclusions that held independent of the variability in site and size of resection. Also, the inclusion of patients without VOTC lesion provided a benchmark against which to compare the signature of visual function in those with a VOTC resection.

Unsurprisingly, we have been unable to discern, microgenetically, the process by which the sufficiency of a single hemisphere emerges and the extent to which the trajectory might mirror that of normal development. In a detailed longitudinal study over a period of 3 years, we monitored changes in behavior as well as EVC and category-selectivity in patient, U.D., with an extensive right occipitotemporal resection (Table 1 ). Whereas there was no visual field remapping and a persistent hemianopia, object-and scene-selective regions in the intact LH were stable early on and retained their stability, whereas face-selective regions emerged slightly later and evinced competition for cortical representation with word-selective regions in the preserved LH during this period (Liu et al., 2018). We note here that the reported plasticity of the left VOTC in patient U.D. is not inconsistent with the absence of large-scale interhemispheric reorganization uncovered here. In particular, the competition between face-and word-selectivity in adjacent extrastriate regions is consistent with enhanced within-hemisphere plasticity because of the absence of interhemispheric reorganization of category-selectivity.

Many questions remain to be answered. Longitudinal investigations from presurgical state through postsurgical changes will be highly informative and additional cases, even if crosssectional, will permit more definitive conclusions regarding the factors that affect prognosis. Having established that visuoperceptual behaviors and normal cortical reorganization are possible following resections in childhood and adolescence, detailed investigations to uncover the mechanisms, either cortical or subcortical, that support the functional restitution in these patients are important to elucidate further the nature of brain-behavior reorganization.

\section{References}

Adolphs R (2016) Human lesion studies in the 21st century. Neuron 90:1151-1153.

Alpherts WC, Vermeulen J, Hendriks MP, Franken ML, van Rijen PC, Lopes da Silva FH, van Veelen CW (2004) Long-term effects of temporal lobectomy on intelligence. Neurology 62:607-611.

Arcaro MJ, Livingstone MS (2017) A hierarchical, retinotopic protoorganization of the primate visual system at birth. Elife 6:e26196.

Arcaro MJ, Schade PF, Vincent JL, Ponce CR, Livingstone MS (2017) Seeing faces is necessary for face-domain formation. Nat Neurosci 20: $1404-1412$.

Barton JJS, Corrow SL (2016) Selectivity in acquired prosopagnosia: the segregation of divergent and convergent operations. Neuropsychologia 83:76-87.

Barttfeld P, Abboud S, Lagercrantz H, Adén U, Padilla N, Edwards AD, Cohen L, Sigman M, Dehaene S, Dehaene-Lambertz G (2018) A lateral-tomesial organization of human ventral visual cortex at birth. Brain Struct Funct 223:3107-3119.

Bavelier D, Levi DM, Li RW, Dan Y, Hensch TK (2010) Removing brakes on adult brain plasticity: from molecular to behavioral interventions. J Neurosci 30:14964-14971.

Bi Y, Wang X, Caramazza A (2016) Object domain and modality in the ventral visual pathway. Trends Cogn Sci 20:282-290.

Bourne JA (2010) Unravelling the development of the visual cortex: implications for plasticity and repair. J Anat 217:449-468.

Bracci S, Op de Beeck H (2016) Dissociations and associations between shape and category representations in the two visual pathways. J Neurosci 36:432-444.

Buckley RT, Morgan T, Saneto RP, Barber J, Ellenbogen RG, Ojemann JG (2014) Dysphagia after pediatric functional hemispherectomy. J Neurosurg Pediatr 13:95-100.

Buonomano DV, Merzenich MM (1998) Cortical plasticity: from synapses to maps. Annu Rev Neurosci 21:149-186.

Busigny T, Graf M, Mayer E, Rossion B (2010) Acquired prosopagnosia as a face-specific disorder: ruling out the general visual similarity account. Neuropsychologia 48:2051-2067.

Cai Q, Lavidor M, Brysbaert M, Paulignan Y, Nazir TA (2008) Cerebral lateralization of frontal lobe language processes and lateralization of the posterior visual word processing system. J Cogn Neurosci 20:672-681.

Cang J, Rentería RC, Kaneko M, Liu X, Copenhagen DR, Stryker MP (2005) Development of precise maps in visual cortex requires patterned spontaneous activity in the retina. Neuron 48:797-809.

Cang J, Niell CM, Liu X, Pfeiffenberger C, Feldheim DA, Stryker MP (2008) Selective disruption of one Cartesian axis of cortical maps and receptive fields by deficiency in ephrin-As and structured activity. Neuron 57:511523.

Cohen L, Dehaene S, Naccache L, Lehéricy S, Dehaene-Lambertz G, Hénaff M-A, Michel F (2000) The visual word form area: spatial and temporal characterization of an initial stage of reading in normal subjects and posterior split-brain patients. Brain 123:291-307.

Cohen L, Lehéricy S, Henry C, Bourgeois M, Larroque C, Sainte-Rose C, Dehaene S, Hertz-Pannier L (2004) Learning to read without a left occipital lobe: right-hemispheric shift of visual word form area. Ann Neurol 56:890-894.

Crawford JR, Howell DC (1998) Comparing an individual's test score against norms derived from small samples. Clin Neuropsychol 12: 482-486.

Croydon A, Pimperton H, Ewing L, Duchaine BC, Pellicano E (2014) The Cambridge face memory test for children (CFMT-C): a new tool for measuring face recognition skills in childhood. Neuropsychologia 62:6067.

Damásio AR, Lima A, Damásio H (1975) Nervous function after right hemispherectomy. Neurology 25:89-93.

Deen B, Richardson H, Dilks DD, Takahashi A, Keil B, Wald LL, Kanwisher NG, Saxe RR (2017) Organization of high-level visual cortex in human infants. Nat Commun 8:13995.

Dehaene S, Cohen L, Morais J, Kolinsky R (2015) Illiterate to literate: behavioural and cerebral changes induced by reading acquisition. Nat Rev Neurosci 16:234-244. 
Dehaene-Lambertz G, Monzalvo K, Dehaene S (2018) The emergence of the visual word form: longitudinal evolution of category-specific ventral visual areas during reading acquisition. PLOS Biol 16:e2004103.

de Koning T, Versnel H, Jennekens-Schinkel A, van Schooneveld MM, Dejonckere PH, van Rijen PC, van Nieuwenhuizen O (2009) Language development before and after temporal surgery in children with intractable epilepsy. Epilepsia 50:2408-2419.

Devlin JT, Jamison HL, Gonnerman LM, Matthews PM (2006) The role of the posterior fusiform gyrus in reading. J Cogn Neurosci 18:911-922.

Emberson LL, Crosswhite SL, Richards JE, Aslin RN (2017) The lateral occipital cortex is selective for object shape, not texture/color, at six months. J Neurosci 37:3698-3703.

Engel J (1993) Surgical treatment of the epilepsies, Ed 2. Philadelphia: Lippincott-Raven.

Epstein R, Kanwisher N (1998) A cortical representation of the local visual environment. Nature 392:598-601.

Farah MJ, Rabinowitz C, Quinn GE, Liu GT (2000) Early commitment of neural substrates for face recognition. Cogn Neuropsychol 17:117-123.

Field DJ, Hayes A, Hess RF (1993) Contour integration by the human visual system: evidence for a local "association field". Vision Res 33:173-193.

Freud E, Culham JC, Plaut DC, Behrmann M (2017a) The large-scale organization of shape processing in the ventral and dorsal pathways. eLife 6:e27576.

Freud E, Ganel T, Shelef I, Hammer MD, Avidan G, Behrmann M (2017b) Three-dimensional representations of objects in dorsal cortex are dissociable from those in ventral cortex. Cereb Cortex 27:422-434.

Gauthier I, Behrmann M, Tarr MJ (1999) Can face recognition really be dissociated from object recognition? J Cogn Neurosci 11:349-370.

Geskin J, Behrmann M (2018) Congenital prosopagnosia without object agnosia: a literature review. Cogn Neuropsychol 35:4-54.

Glover GH (1999) Deconvolution of impulse response in event-related BOLD fMRI. Neuroimage 9:416-429.

Golarai G, Ghahremani DG, Whitfield-Gabrieli S, Reiss A, Eberhardt JL, Gabrieli JDE, Grill-Spector K (2007) Differential development of highlevel visual cortex correlates with category-specific recognition memory. Nat Neurosci 10:512-522.

Golarai G, Liberman A, Yoon JM, Grill-Spector K (2010) Differential development of the ventral visual cortex extends through adolescence. Front Hum Neurosci 3:80.

Golarai G, Liberman A, Grill-Spector K (2017) Experience shapes the development of neural substrates of face processing in human ventral temporal cortex. Cereb Cortex 27:1229-1244.

Grill-Spector K, Malach R (2004) The human visual cortex. Annu Rev Neurosci 27:649-677.

Grill-Spector K, Weiner KS (2014) The functional architecture of the ventral temporal cortex and its role in categorization. Nat Rev Neurosci 15: $536-548$.

Hadad B, Maurer D, Lewis TL (2010) The effects of spatial proximity and collinearity on contour integration in adults and children. Vision Res 50:772-778.

Hasson U, Levy I, Behrmann M, Hendler T, Malach R (2002) Eccentricity bias as an organizing principle for human high-order object areas. Neuron 34:479-490.

Haxby JV, Gobbini MI, Furey ML, Ishai A, Schouten JL, Pietrini P (2001) Distributed and overlapping representations of faces and objects in ventral temporal cortex. Science 293:2425-2430.

Hensch TK (2005) Critical period mechanisms in developing visual cortex. Curr Top Dev Biol 69:215-237.

Hensch TK (2016) The power of the infant brain. Sci Am 314:64-69.

Kaas JH (1991) Plasticity of sensory and motor maps in adult mammals. Annu Rev Neurosci 14:137-167.

Kamm J, Boles Ponto LL, Manzel K, Gaasedelen OJ, Nagahama Y, Abel T, Tranel D (2018) Temporal lobe asymmetry in FDG-PET uptake predicts neuropsychological and seizure outcomes after temporal lobectomy. Epilepsy Behav 78:62-67.

Kanwisher N, McDermott J, Chun MM (1997) The fusiform face area: a module in human extrastriate cortex specialized for face perception. J Neurosci 17:4302-4311.

Kelly KR, Gallie BL, Steeves JK (2012) Impaired face processing in early monocular deprivation from enucleation. Optom Vis Sci 89:137-147.

Konen CS, Behrmann M, Nishimura M, Kastner S (2011) The functional neuroanatomy of object agnosia: a case study. Neuron 71:49-60.
Kriegeskorte N, Mur M, Bandettini P (2008) Representational similarity analysis: connecting the branches of systems neuroscience. Front Syst Neurosci 2:4.

Le Grand R, Mondloch CJ, Maurer D, Brent HP (2001) Neuroperception: early visual experience and face processing. Nature 410:890.

Le Grand R, Mondloch CJ, Maurer D, Brent HP (2003) Expert face processing requires visual input to the right hemisphere during infancy. Nat Neurosci 6:1108-1112.

Le Grand R, Mondloch CJ, Maurer D, Brent HP (2004) Impairment in holistic face processing following early visual deprivation. Psychol Sci $15: 762-768$

Lewis TL, Maurer D (2005) Multiple sensitive periods in human visual development: evidence from visually deprived children. Dev Psychobiol 46:163-183.

Lewis TL, Ellemberg D, Maurer D, Wilkinson F, Wilson HR, Dirks M, Brent HP (2002) Sensitivity to global form in glass patterns after early visual deprivation in humans. Vision Res 42:939-948.

Liu TT, Behrmann M (2017) Functional outcomes following lesions in visual cortex: implications for plasticity of high-level vision. Neuropsychologia 105:197-214.

Liu TT, Nestor A, Vida MD, Pyles JA, Patterson C, Yang Y, Yang FN, Freud E, Behrmann M (2018) Successful reorganization of category-selective visual cortex following occipito-temporal lobectomy in childhood. Cell Rep 24:1113-1122.e6.

Livingstone MS, Vincent JL, Arcaro MJ, Srihasam K, Schade PF, Savage T (2017) Development of the macaque face-patch system. Nat Commun 8:14897.

Malach R, Reppas JB, Benson RR, Kwong KK, Jiang H, Kennedy WA, Ledden PJ, Brady TJ, Rosen BR, Tootell RB (1995) Object-related activity revealed by functional magnetic resonance imaging in human occipital cortex. Proc Natl Acad Sci U S A 92:8135-8139.

Martin A (2007) The representation of object concepts in the brain. Annu Rev Psychol 58:25-45.

Meekes J, Braams O, Braun KP, Jennekens-Schinkel A, van Nieuwenhuizen O (2013) Verbal memory after epilepsy surgery in childhood. Epilepsy Res 107:146-155.

Nestor A, Plaut DC, Behrmann M (2016) Feature-based face representations and image reconstruction from behavioral and neural data. Proc Natl Acad Sci U S A 113:416-421.

Nishimura M, Scherf KS, Zachariou V, Tarr MJ, Behrmann M (2015) Size precedes view: developmental emergence of invariant object representations in lateral occipital complex. J Cogn Neurosci 27:474-491.

Otsuka Y, Nakato E, Kanazawa S, Yamaguchi MK, Watanabe S, Kakigi R (2007) Neural activation to upright and inverted faces in infants measured by near infrared spectroscopy. Neuroimage 34:399-406.

Pahs G, Rankin P, Helen Cross J, Croft L, Northam GB, Liegeois F, Greenway S, Harrison S, Vargha-Khadem F, Baldeweg T (2013) Asymmetry of planum temporale constrains interhemispheric language plasticity in children with focal epilepsy. Brain 136:3163-3175.

Ponce CR, Hartmann TS, Livingstone MS (2017) End-stopping predicts curvature tuning along the ventral stream. J Neurosci 37:648-659.

Price CJ, Devlin JT (2011) The interactive account of ventral occipitotemporal contributions to reading. Trends Cogn Sci 15:246-253.

Rosenthal G, Tanzer M, Simony E, Hasson U, Behrmann M, Avidan G (2017) Altered topology of neural circuits in congenital prosopagnosia. eLife 6:e25069.

Saygin ZM, Osher DE, Norton ES, Youssoufian DA, Beach SD, Feather J, Gaab N, Gabrieli JD, Kanwisher N (2016) Connectivity precedes function in the development of the visual word form area. Nat Neurosci 19: $1250-1255$.

Scherf KS, Behrmann M, Humphreys K, Luna B (2007) Visual categoryselectivity for faces, places and objects emerges along different developmental trajectories. Dev Sci 10:F15-F30.

Scherf KS, Luna B, Avidan G., Behrmann M (2011) 'What' precedes 'Which': Developmental neural tuning in face- and place-related cortex. Cereb Cortex 21:1963-1980.

Sigal YM, Bae H, Bogart LJ, Hensch TK, Zhuang X (2019) Structural maturation of cortical perineuronal nets and their perforating synapses revealed by superresolution imaging. Proc Natl Acad Sci U S A 116:70717076 .

Smith MA, Bair W, Movshon JA (2002) Signals in macaque striate cortical 
neurons that support the perception of glass patterns. J Neurosci 22:8334-8345.

Smith MA, Kohn A, Movshon JA (2007) Glass pattern responses in macaque V2 neurons. J Vis 7(3):5 1-15.

Srihasam K, Vincent JL, Livingstone MS (2014) Novel domain formation reveals proto-architecture in inferotemporal cortex. Nat Neurosci 17:1776-1783.

Sugita Y (2008) Face perception in monkeys reared with no exposure to faces. Proc Natl Acad Sci U S A 105:394-398.

Sun YJ, Liu BH, Tao HW, Zhang LI (2019) Selective strengthening of intracortical excitatory input leads to receptive field refinement during auditory cortical development. J Neurosci 39:1195-1205.

Syken J, Grandpre T, Kanold PO, Shatz CJ (2006) PirB restricts oculardominance plasticity in visual cortex. Science 313:1795-1800.

Thomas C, Avidan G, Humphreys K, Jung KJ, Gao F, Behrmann M (2009) Reduced structural connectivity in ventral visual cortex in congenital prosopagnosia. Nat Neurosci 12:29-31.

Tomasello R, Wennekers T, Garagnani M, Pulvermüller F (2019) Recruitment of visual cortex for language processing in blind individuals is explained by Hebbian learning. Sci Rep 9:3579.

Tracy JI, Hampstead BM, Sathian K (2014) Cognitive plasticity in neurologic disorders. New York: Oxford UP.
Van der Haegen L, Cai Q, Brysbaert M (2012) Colateralization of Broca's area and the visual word form area in left-handers: fMRI evidence. Brain Lang 122:171-178.

Vargha-Khadem F, Isaacs E, Muter V (1994) A review of cognitive outcome after unilateral lesions sustained during childhood. J Child Neurol 9:67-73.

Wandell BA, Smirnakis SM (2009) Plasticity and stability of visual field maps in adult primary visual cortex. Nat Rev Neurosci 10:873-884.

Weiner KS, Golarai G, Caspers J, Chuapoco MR, Mohlberg H, Zilles K, Amunts K, Grill-Spector K (2014) The mid-fusiform sulcus: a landmark identifying both cytoarchitectonic and functional divisions of human ventral temporal cortex. Neuroimage 84:453-465.

Weiner KS, Jonas J, Gomez J, Maillard L, Brissart H, Hossu G, Jacques C, Loftus D, Colnat-Coulbois S, Stigliani A, Barnett MA, Grill-Spector K, Rossion B (2016) The face-processing network is resilient to focal resection of human visual cortex. J Neurosci 36:8425-8440.

Werth R (2006) Visual functions without the occipital lobe or after cerebral hemispherectomy in infancy. Eur J Neurosci 24:2932-2944.

Yeatman JD, Dougherty RF, Ben-Shachar M, Wandell BA (2012) Development of white matter and reading skills. Proc Natl Acad Sci U S A 109: E3045-53. 